\title{
Upwind Horizontal Axis Wind Turbine Output Power Optimization via Artificial Intelligent Control System
}

\author{
Endalew Ayenew Haile ${ }^{1, *}$, Getachew Biru Worku², Asrat Mulatu Beyene', Milkias Berhanu Tuka \\ ${ }^{1}$ Center of Excellence for Sustainable Energy, College of Electrical and Mechanical Engineering, Addis Ababa Science and Technology \\ University, Addis Ababa, Ethiopia \\ ${ }^{2}$ Electrical Power and Control Engineering, School of Electrical and Computer Engineering, Adama Science and Technology University, \\ Adama, Ethiopia
}

Email address:

endalew.ayenew@astu.edu.et (E. A. Haile),gbiru@yahoo.co.uk (G. B. Worku.), asrat.mulatu@aastu.edu.et (A. M. Beyene), milkiasber@gmail.com (M. B. Tuka)

${ }^{*}$ Corresponding author

\section{To cite this article:}

Endalew Ayenew Haile, Getachew Biru Worku, Asrat Mulatu Beyene, Milkias Berhanu Tuka. Upwind Horizontal Axis Wind Turbine Output Power Optimization via Artificial Intelligent Control System. Automation, Control and Intelligent Systems. Vol. 9, No. 1, 2021 , pp. 6-21. doi: 10.11648/j.acis.20210901.13

Received: January 6, 2021; Accepted: January 16, 2021; Published: January 25, 2021

\begin{abstract}
Power capturing capacity is one of the key performance indicators of wind turbines. This article presents a study done on the optimization of output power of upwind horizontal axis wind turbine using artificially intelligent control system. The study shows how blade tip speed ratio $(\lambda)$ and pitch angle $(\beta)$ are optimized to increase wind turbines power conversion coefficient $\left(\mathrm{C}_{\mathrm{p}}\right)$ which increases the output power. An artificial intelligence system named Mandani fuzzy inference system (MFIS) was applied to optimize the power conversion coefficient in combination with blade pitch actuator control. To this end, a novel optimization technique is designed that maximizes the power harvesting ability of wind turbines by updating the parameters of the membership functions of fuzzy logic found in the MFIS. With the application of this optimization method, a power conversion coefficient $C_{p}$ of 0.5608 value is achieved at optimal values of $\lambda$ and $\beta$. As a result, the energy harvesting ability of the wind turbine considered is improved by $16.74 \%$. This study clearly shows that the wind energy harvesting capacity of wind turbines can be enhanced via optimization techniques that could be further implemented in wind turbine blade pitch drive system. Thus, this novel optimization method creates further insights for the wind energy industry in reducing the cost of energy generation.
\end{abstract}

Keywords: Energy Maximization, Upwind HAWT, MFIS, Wind Turbine Performance

\section{Introduction}

The wind turbine power capturing capacity is one of its main performances. Variable-speed and variable-pitch horizontal axis wind turbines (HAWT) have a good capacity of power capturing from the wind. These types of wind turbines use typically two control strategies; speed control and blade pitch angle control. When the wind speed is between cut-in and rated values, the speed control can repeatedly alter the rotor speed to maintain it at a value around rated speed, and hence, the turbine output power will be optimized. While the wind speed becomes above the rated speed, blade pitch angle adjustment is mandatory to limit rotor output power to the rated value by maintaining the rotor speed constant at the rated value.

In addition to the wind speed, major parameters of the wind turbine to harvest maximum energy from the kinetic energy of the wind are mainly related to blade aerofoil. These are blade length, blade chord length, blade twist angle (sum of pitch angle and attack angle), and turbine's lift coefficient to drag coefficient ratio. To maximize the power output of the wind turbine rotor, research has focused on the blade aerofoil shape known as a lifting surface. Devices that improve blade aerodynamic such as small skewed fins (vortex generators) 
are inserted into modern wind turbine blades $[1,2]$. This is to create a thin current of turbulent air on the surface of the blade aerofoil and prevent the aerofoil from stalling at low wind speed. The turbulent air delays airflow separation or mixes the boundary of the air layer (laminar and turbulent flows on the upper surface of blade aerofoil) with faster-moving air from the free stream. This reduces wake on the upper surface of blade aerofoil, enhances lifting force, and reduces the effect of aerodynamic drag force and losses due to it; and hence improves the wind turbine energy capturing capacity.

The wind turbine rotor can harvest only a fraction of power available in the wind due to the airflow requirements. The ratio of harvested power by wind turbine rotor to extractable power over an area swept by the turbine blade in the wind is called a power conversion coefficient $\left(\mathrm{C}_{\mathrm{p}}\right)$. According to Betz's limit, theoretically, the maximum value of the power conversion coefficient from wind kinetic energy to mechanical energy is $0.593[3,4]$.

The objective of this study is to optimize the power harvesting capacity of the upwind HAWT through optimization of $\mathrm{C}_{\mathrm{p}}$ using an artificial intelligent control system called the Mamdani fuzzy inference system (MFIS). The wind speed is naturally an uncertain meteorological phenomenon. It causes uncertainty in power harvesting. The fuzzy logic is a very suitable tool to handle such uncertain conditions. The MFIS can map a non-linearity between its inputs and outputs. The major contributions of this study are

1. Use of MFIS scheme for $C_{p}$ optimization with the controller of a wind turbine blade pitch actuator.

2. Optimization of wind turbine output power in wind energy conversion systems (WECS) by robust handling of uncertain wind speed.

3. Introduction of advanced and simplified technique to optimally update parameters of the membership function of fuzzy logic in the proposed scheme.

4. Deployment of the proposed optimization tool, an interesting improvement in the output power of the wind turbine is achieved.

In the next parts of this paper, the Literature Review, Methodology, the Optimization Technique, Results and Discussion of the research are presented.

\section{Related Literature Review}

Optimization of the power harvesting ability of the wind turbine was carried by many researchers independently using blade element momentum theory (BEMT). Glauert attained a value of 0.416 and Joukowky got 0.5 values for the power conversion coefficient [5]. Gens N. S applied the modified momentum equation and got a better power conversion coefficient than Glauert's and Joukowky's results in HAWT [5]. The optimal actuator disk theory of HAWT was developed by Glauert in 1935 . Theoretically, he claimed $0.416-0.587$ value of the power conversion coefficient [1]. Currently, BEMT is an industry-standard used by all producers of the wind turbine and its blade [5]. Typical effects of the number of turbine blades and mechanical design of blades aerofoil drag-to-lift ratio on the optimal power conversion coefficient of a horizontal axis wind turbine (HAWT) were presented by Robert E. Wilson and his colleagues [6]. As per the result of their work, the power conversion coefficient is around 0.5 . Also, Ranjan Vepa stated that according to the aerodynamic design of the turbine blade and choice of its profile, three-bladed HAWT can convert $35 \%$ to $38 \%$ of wind energy to mechanical energy [8]. But, in practice, wind turbine converts only $20 \%$ to $40 \%$ of the wind energy to mechanical energy [7]. Therefore, to improve the power harvesting capacity of the HAWT, an optimization technique for $\mathrm{C}_{\mathrm{p}}$ is required.

The enhanced value of $C_{p}$ upsurges the wind turbine productivity and hence reduce the cost of energy production. Different algorithms of maximum power point track (MPPT) for performance improvement of WECS were discussed in the literature [9-11]. To mention some, tip speed ratio control, power signal feedback control, perturb and observe, hill climb search, optimal torque control, hybrid of MPPT algorithms, and artificial intelligence were debated. The MPPT-curve of the wind turbine was improved by Lyapunov-function based PI control [12]. Accordingly, the 0.472 value of $C_{p}$ was achieved. In another study of MPPT on the permanent magnet synchronous generator employing conventional optimum torque control with a toque error feed-forward algorithm, a $\mathrm{C}_{\mathrm{p}}$ value of 0.423 was achieved on WECS [13]. According to the researches indication, the maximum achievable value of $\mathrm{C}_{\mathrm{p}}$ ranges between 0.2 and 0.4 for wind turbines with three or more blades $[14,15]$. Neuro-fuzzy methods were applied to estimate the $C_{p}$ of the wind turbine and the maximum estimated value was 0.352 [16]. Radial base function neural network along with optimal torque control was employed for MPPT of double fed induction generator (DFIG) using WECS and 0.52 optimal $C_{p}$ is attained [17]. The simulation result of the study on the optimized pathway, aero-generator modeling, and control upon wind turbine driven by PMSG shows a power conversion coefficient of 0.429 [18]. The optimal value of $\mathrm{C}_{\mathrm{p}}$ of the three-bladed wind turbines is equal to 0.47 [19]. A value of $2.36 \%$ improvement in power is obtained by using the maximum extraction technique with power optimization and control [20]. Tony Hawkins [21] implemented robust estimation and Lyapunov extremum seeking control and extracted $47.25 \%$ of power in the wind. As per [22], optimally designed wind turbines with two or three blades can have $\mathrm{C}_{\mathrm{p}}$ above 0.4 .

Based on the above discussions on the mechanical design of the wind turbine blade, the HAWT has a good capacity to harvest power from wind. However, due to the uncertain environment, system operational limitation like different losses in the wind energy conversion system (e.g. turbine blade tip loss, and mechanical loss), and controller inaccuracy, generally, wind turbines convert only about $30 \%$ to $35 \%$ of the available wind energy into electrical energy [8].

The summary of review results related to the recent studies of maximization of output power of the wind turbine is 
presented in Table 1.

Table 1. Summary of Review Results Related to Recent Works in Wind Turbine Output Power Maximization.

\begin{tabular}{lll}
\hline Reference & Objective & Method \\
\hline$[17]$ & Maximum power harvesting & RBFNN control strategy of MPPT of WECS \\
{$[23]$} & Search maximum power point (SMPP) of variable-speed & SELF-ADAPTIVE perturb and observe algorithm for MPPT \\
\hline$[24]$ & WECS & 0.4800 \\
{$[25]$} & Optimize and control the HAWT & PSO with a neuro-fuzzy controller \\
{$[26]$} & MPPT for wind turbine & Optimal torque control \\
{$[27]$} & Optimize power capture by wind turbine & RBFNN technique \\
{$[28]$} & Wind turbine output power improvement & fuzzy inference based Generator torque control \\
{$[29]$} & Maximize output power of SCIG based WECS & Fuzzy Logic Controller \\
{$[30]$} & Extract maximum power from the wind & $\lambda$ control via ANN-PSO for MPPT of small wind turbine \\
{$[31]$} & Extract maximum energy from the wind & Fuzzy logic control based on HCSM \\
{$[32]$} & MPPT for WECS & $\lambda$ control via GA Optimization \\
\hline
\end{tabular}

\section{Methodology}

The wind turbine power conversion coefficient $\left(C_{p}(\lambda, \beta)\right)$ is associated with the tip speed ratio $(\lambda)$ and the pitch angle $(\beta)$ of the turbine blade. The optimal power can be captured only under an optimal value of $\mathrm{C}_{\mathrm{p}}(\lambda, \beta)$ at optimal values of $\lambda$ and $\beta$.

The proposed strategy is employed with real-time wind speed data that was collected from the Adama-II wind farm North site, Adama, Ethiopia. The data was collected at 10 meters above ground from January to June 2020. This site is geographically located at the latitude of $8^{\circ} 18^{\prime} 35.5^{\prime \prime} \mathrm{N}$, the longitude of $38^{\circ} 53^{\prime} 4.2^{\prime \prime} \mathrm{E}$ and elevation of $1712 \mathrm{~m}$ above sea level in Ethiopia about $95 \mathrm{~km}$ far away to the southeast of Addis Ababa. The picture of the site is presented in Figure 1. The data is collected using the METEO-40 data logger and is logged every 10 minutes. Every day, the METEO-40 data logger stores 144 samples. This data is presented in Figure 2 after extrapolated to the hub height of the SANY SE7715 wind turbine. To validate the result of this study, the factory test report data of the SE7715 wind turbine is used. Practically, the generator's output power and corresponding $\mathrm{C}_{\mathrm{p}}$, and rotor speed data were recorded from the SCADA system in the control room. The analysis of data and optimization of $C_{p}(\lambda, \beta)$ of the wind turbine was done by using MATLAB software. The simulation and experimental results are compared.

The wind turbine rotor output power $\left(\mathrm{P}_{\mathrm{r}}\right)$ in watt expressed in $(1)$ as a function of wind speed $\left(V_{a}\right)$ in $\mathrm{m} / \mathrm{s}$, air density $(\rho)$ in $\mathrm{kg} / \mathrm{m}^{3}$, and the swept area $\left(\mathrm{A}=\pi \mathrm{R}^{2}\right)$ in $\mathrm{m}^{2}$ with a rotor radius $\mathrm{R}$ $[33,34]$.

$$
\begin{gathered}
\mathrm{P}_{\mathrm{r}}=0.5 \rho \pi \mathrm{R}^{2} \mathrm{~V}_{\mathrm{a}}^{3} C_{p}(\lambda, \beta) \\
\lambda=\frac{R \omega}{V_{a}}
\end{gathered}
$$

Equation (1) indicates the rotor output power depends on and reliant on the pitch angle and the tip speed ratio. Minor variations in $\lambda$ and $\beta$ can change the turbine rotor output power. As was discussed in the literature review part of this study, many of the parameters of the wind turbine that influence the energy harvesting ability of the turbine are directly or indirectly related to the blade pitch angle $(\beta)$. The effect of the blade length in combination with rotor speed $(\omega)$ in $\mathrm{rad} / \mathrm{s}$ and the wind speed on the energy harvesting are governed by the blade tip speed ratio as given in (2).

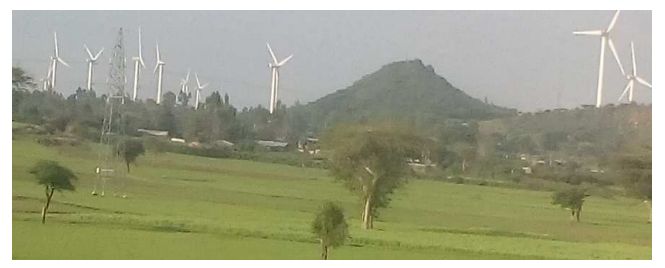

Figure 1. Adama-II Wind Farm Site.

For variable speed and variable pitch regulated HAWT, different but equivalent empirical relations for power conversion coefficient $\left(C_{P}(\lambda, \beta)\right)$ are presented as a function of $\lambda$ and $\beta$ in $[8,22]$. One of such empirical relations [35] is:

$$
C_{p}(\lambda, \beta)=0.5176\left(\frac{116}{\lambda_{b}}-0.4 \beta-5\right) \cdot e^{-\frac{21}{\lambda_{b}}}+0.0068 \lambda
$$

Where

$$
\frac{1}{\lambda_{b}}=\frac{1}{\lambda+0.08 \beta}-\frac{0.035}{\beta^{3}+1}
$$

According to the wind speed condition, pitch angle $(\beta)$ could be adjusted by the pitch actuator controller; $\beta$ in (3) is approximately set to zero degrees in the case of the wind speed is below the nominal speed and hence $C_{p}(\lambda, \beta)$ depends only on the $\lambda$. This is depicted in Figure 3 for different values of $\beta$ and computed $\lambda$ values for the SE7715 wind turbine, which shows a decrease of $\mathrm{C}_{\mathrm{p}}(\lambda, \beta)$ with an increase of $\beta$. To capture maximum power, the turbine should operate at its optimal $\mathrm{C}_{\mathrm{p}}(\lambda, \beta)$. To optimize $\mathrm{C}_{\mathrm{p}}(\lambda, \beta)$, a fuzzy logic control technique is employed. The fuzzy logic is the utmost suitable technique for power extraction from the wind. Because the fuzzy logic can handle an uncertain behavior of the wind speed in energy harvesting by the wind turbine. The key pro of a fuzzy logic-based control tool is that it does not need an exact mathematical model of the system. In the next section, the optimization technique for the output power of the wind 
turbine is presented.

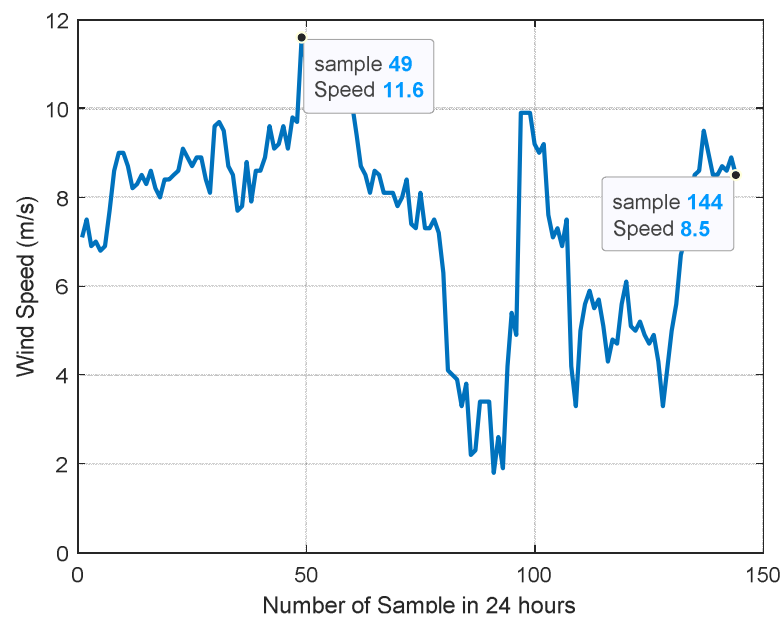

(a)

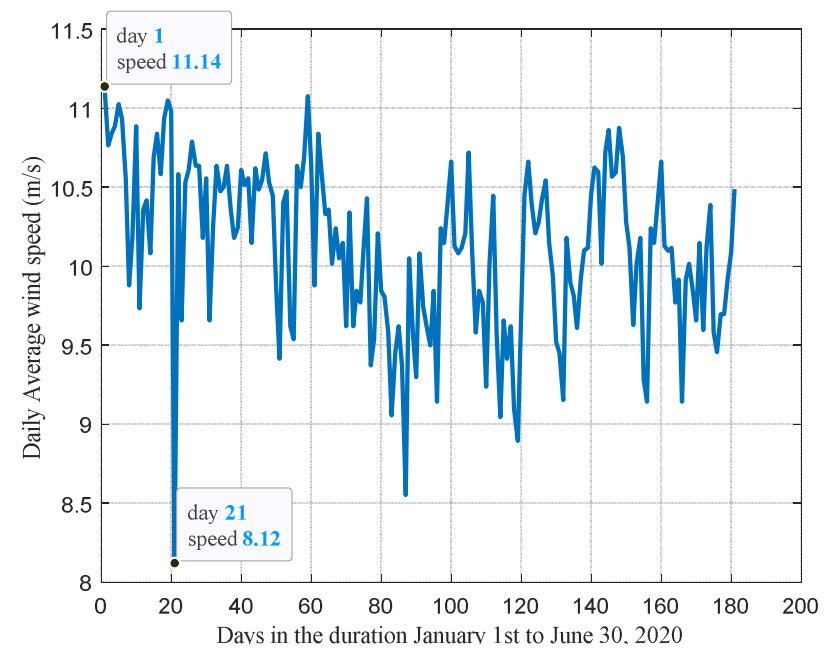

(b)

Figure 2. Average Wind Speed Data: (a) every 10 minutes of Jan 21, 2020, (b) Daily in the duration of January to June 2020.

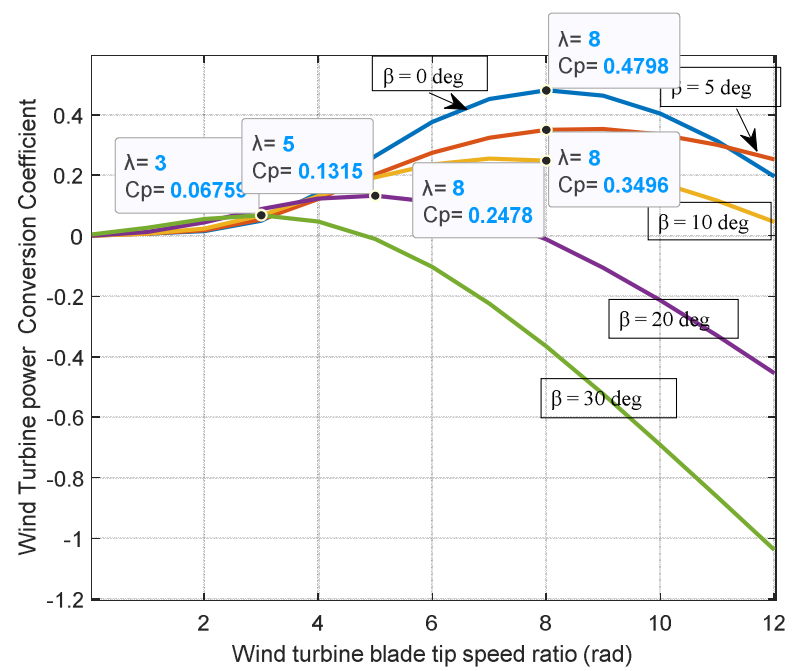

Figure 3. Wind Power to Mechanical Power Conversion Coefficient as a function of $\lambda$ and at specific $\beta$ of SE7715 Wind Turbine.

\section{Output Power Optimization Technique}

The Mamdani fuzzy inference system (MFIS) is proposed to maximize the power extraction capacity of off-grid HAWT from the wind. The primary objective of using MFIS is to maximize wind power conversion efficiency- $C_{p}(\lambda, \beta)$ of a variable speed horizontal axis wind turbine. The MFIS is integrated with the wind turbine blade pitch actuator control system. The MFIS was built by E. Manani in 1974 for the first time [36].

As revealed in Figure 4 for the proposed optimization scheme, the wind speed data from an anemometer and a power error are the inputs to the pitch angle actuator controller. When the actual wind speed is far from the nominal value, the error between generator output power $\left(\mathrm{P}_{\mathrm{ge}}=\eta_{\mathrm{g}} \eta_{\mathrm{gb}} \mathrm{P}_{\mathrm{r}}\right.$; for $\eta_{\mathrm{g}}$ and $\eta_{\mathrm{gb}}$ are the efficiency of generator and gearbox respectively) and generator nominal $\left(\mathrm{P}_{\text {ref }}\right)$ power will be non-zero. Based on this error and wind speed status, the turbine blade is pitched by the actuator and hence $\beta$ and rotor speed are optimally regulated. The $\beta$ and $\lambda$ from the wind turbine are inputs to the MFIS model to optimize $\mathrm{C}_{\mathrm{p}}(\lambda, \beta)$. Next, the detail of the MFIS based optimization technique and wind turbine blade pitch actuator control system is presented.

\subsection{Pitch Angle Control Mechanism}

The wind turbine blade pitch actuator control is formulated based on a fuzzy logic controller. It generates a desired command pitch angle $\left(\beta_{\mathrm{d}}\right)$ as seen in Figure 5 and Figure 4. The hydraulic actuator for the wind turbine blade pitch system is modeled using the first-order model as follows [37].

$$
\begin{gathered}
\tau \frac{d \beta}{d t}=\Delta \beta \Rightarrow \frac{\beta(s)}{\Delta \beta(s)}=\frac{1}{\tau s} \text { For } \Delta \beta=\beta_{d}-\beta ; \\
\frac{\beta(s)}{\beta_{d}(s)}=\frac{1}{\tau s+1}
\end{gathered}
$$

Where $\tau$ is the pitch actuator time constant and usually ranges between 0.2 to 0.25 seconds [37]. The specification of the SE7715 wind turbine blade pitch actuator is presented in Table 2.

Considering these specifications, the pitch actuator controller is designed. For normal operation of the wind turbine, with pitch actuator running at $5 \%$ sec with $0.0133 \%$ accuracy, the error is

$$
\beta_{d}-\beta=0.0128 * 90^{\circ}=1.15^{\circ} .
$$

Hence the time constant is computed as

$$
\tau=\left(\beta_{d}-\beta\right) /(d \beta / d t)=\frac{1.15^{\circ}}{5^{\circ} / \mathrm{sec}}=0.23 \mathrm{sec} .
$$

The input of the fuzzy logic controller is the power error $\left(\mathrm{P}_{\mathrm{e}}\right)$ between the generator's actual output power $\left(\mathrm{P}_{\text {ge }}\right)$ and the reference power $\left(\mathrm{P}_{\text {ref }}\right)$, and the real measured wind speed $\left(\mathrm{V}_{\mathrm{a}}\right)$ at any instant time. $\mathrm{P}_{\mathrm{e}}$ was calculated as follows.

$$
\mathrm{P}_{\mathrm{e}}=\mathrm{P}_{\mathrm{ge}}-P_{\text {ref }}
$$

The ranges of $\mathrm{P}_{e}$ and $\mathrm{V}_{\mathrm{a}}$ are depicted in Table 3. $\mathrm{P}_{\mathrm{e}}$ is 
scaled on the base of 1.5 MW, $\mathrm{V}_{\mathrm{a}}$ is scaled on the base of 25 $\mathrm{m} / \mathrm{s}$, and $\beta_{\mathrm{d}}$ is scaled on the base of $90^{\circ}$ The fuzzified linguistic variables of the input to the controller of the blade actuator are presented in Table 3 for EVVB, VVB, VB, B, M, $\mathrm{S}, \mathrm{VS}, \mathrm{VVS}$ ZR are fuzzy subsets that represent extreme very very big, very very big, very big, big, medium, small, very small, very very small, and zero respectively.

The pitch angle controller was designed to have suitable values for the pitch angle input to the power conversion coefficient optimization scheme. Thus, as shown in Table 3, the most dominant eleven Mandani fuzzy logic rules "IF $P_{e}$ is $P_{E j}$ AND $V_{a}$ is $V_{A j}$ THEN $\beta_{d}$ is $\beta_{D j}$ " are used to generate the command input to the blade actuator. $P_{E j}, V_{A j}$, and $\beta_{D j}$ represent universes of a discourse of fuzzy subsets of the error, instant wind speed, and the desired pitch angle respectively. The pitch control traces the status of the wind speed and the power error. The power error is zero starting at the wind speed equal to the rated value onward. As the wind speed increases the pitch command too.

Table 2. Technical parameters of the 1.5MW series SE7715 WTG.

\begin{tabular}{lll}
\hline Parameter & & Parameter value /description \\
\hline & Rated power & $1500 \mathrm{~kW}$ \\
& Rated wind speed & $12 \mathrm{~m} / \mathrm{s}$ \\
& Cut-in wind speed & $3.5 \mathrm{~m} / \mathrm{s}$ \\
& Cut-out wind speed & $25 \mathrm{~m} / \mathrm{s}$ \\
Wind rotor & Height of wheel hub center & $77 \mathrm{~m}$ \\
& Rotor radius & $37.8 \mathrm{~m}$ \\
& Rated rotating speed & $19 \mathrm{rpm}$ \\
& Number of blades & 3 \\
& Variable pitch system & 3 independent controls \\
$\eta_{\mathrm{g} \text { and }} \eta_{\mathrm{gb}}$ & Generator efficiency & 0.97 \\
& Gearbox efficiency & 0.97 \\
Variable pitch system basic & Normal variable pitch speed & $5 \% / \mathrm{s}$ \\
performance & Sudden stop variable pitch speed & $10^{\circ} / \mathrm{s}$ \\
& Variable pitch angle & $0 \sim 90^{\circ}$ \\
\hline
\end{tabular}

Table 3. FIS Rules for Input $P_{e}$ and $\beta_{d}$ of Pitch Actuator Fuzzy Logic Controller.

\begin{tabular}{|c|c|c|c|c|c|}
\hline Wind Speed $\left(V_{a}\right)$ & & Power error $\left(\mathbf{P}_{\mathrm{e}}\right)$ & & Pitch angle $\left(\beta_{d}\right)$ & \\
\hline Ranges & Linguistic Variables & Ranges & Linguistic Variables & Ranges & Linguistic Variables \\
\hline$\left[\begin{array}{ll}0 & 0.14\end{array}\right]$ & $\mathrm{ZR}$ & {$\left[\begin{array}{ll}-1 & -0.97]\end{array}\right.$} & EVVBN & {$\left[\begin{array}{ll}-1 & 0\end{array}\right]$} & EVVBN \\
\hline$\left[\begin{array}{lll}0.14 & 0.20\end{array}\right]$ & VVS & {$\left[\begin{array}{ll}-0.97 & -0.88\end{array}\right]$} & VVBN & {$\left[\begin{array}{ll}-1 & 0\end{array}\right]$} & EVVBN \\
\hline$\left[\begin{array}{ll}0.20 & 0.28\end{array}\right]$ & VS & {$\left[\begin{array}{ll}-0.88 & -0.68\end{array}\right]$} & VBN & {$\left[\begin{array}{ll}0 & 0\end{array}\right]$} & $\mathrm{ZR}$ \\
\hline$\left[\begin{array}{ll}0.28 & 0.36\end{array}\right]$ & $\mathrm{S}$ & {$\left[\begin{array}{ll}-0.68 & -0.32\end{array}\right]$} & $\mathrm{BN}$ & {$\left[\begin{array}{ll}0 & 0\end{array}\right]$} & ZR \\
\hline$\left[\begin{array}{ll}0.36 & 0.42\end{array}\right]$ & M & {$\left[\begin{array}{lll}-0.32 & 0\end{array}\right]$} & $\mathrm{MN}$ & {$\left[\begin{array}{ll}0 & 0\end{array}\right]$} & ZR \\
\hline$\left[\begin{array}{ll}0.53 & 0.60\end{array}\right]$ & VB & {$\left[\begin{array}{ll}0 & 0\end{array}\right]$} & ZR & {$\left[\begin{array}{ll}0 & 0.133\end{array}\right]$} & $\mathrm{S}$ \\
\hline$\left[\begin{array}{ll}0.60 & 0.72\end{array}\right]$ & VVB & {$\left[\begin{array}{ll}0 & 0\end{array}\right]$} & ZR & {$\left[\begin{array}{ll}0.133 & 0.378\end{array}\right]$} & M \\
\hline$\left[\begin{array}{ll}0.72 & 0.80\end{array}\right]$ & EVVB1 & {$\left[\begin{array}{ll}0 & 0\end{array}\right]$} & ZR & {$\left[\begin{array}{lll}0.378 & 0.500\end{array}\right]$} & B \\
\hline$\left[\begin{array}{ll}0.80 & 0.88\end{array}\right]$ & EVVB2 & {$\left[\begin{array}{ll}0 & 0\end{array}\right]$} & ZR & {$\left[\begin{array}{lll}0.500 & 0.611\end{array}\right]$} & VB \\
\hline$\left[\begin{array}{lll}0.86 & 1\end{array}\right]$ & EVVB3 & {$\left[\begin{array}{ll}0 & 0\end{array}\right]$} & ZR & {$\left[\begin{array}{ll}0.611 & 0.700\end{array}\right]$} & VVB \\
\hline
\end{tabular}

\subsection{MFIS Based Optimization Technique}

The degree of the membership functions is the major feature in the computing of the fuzzy logic sets [38]. This study employs fuzzification of inputs $(\lambda$ and $\beta)$ crisps to MFIS and output $\left(C_{p}(\lambda, \beta)=C_{p}\right)$ crisp of the MFIS. As shown in Figure 4 , the MFIS based optimization scheme has four major blocks or stages to process the input-output data pairs.

The first is the fuzzifier of input-output crisp data pairs. As indicated in (7), the triangular-shaped activation function is used to compute membership functions (MFs) of the crisps.

$$
\mu(\zeta)=\left\{\begin{array}{c}
1-\frac{\left|\zeta-\sigma_{j}{ }^{l}\right|}{\sigma_{j}{ }^{l} / j},\left|\zeta-\sigma_{j}{ }^{l}\right| \leq \sigma_{j}{ }^{l} \\
0, \text { elsewhere }
\end{array}\right.
$$

Where $\zeta$ stands for the crisps (inputs $\lambda$ and $\beta$ ) with $\sigma_{j}{ }^{l}$ stands for the center and/or width parameters $\left(\sigma_{\lambda j}{ }^{l}(\mathrm{k})\right.$ and $\sigma_{\beta j}{ }^{l}(\mathrm{k})$ ) of MFs for $\mathrm{\imath}=1,2, \ldots, 25=\mathrm{L}$ is numbers of fuzzy inference rules, $\mathrm{j}=1,2, \ldots$ is fuzzy MFs. 


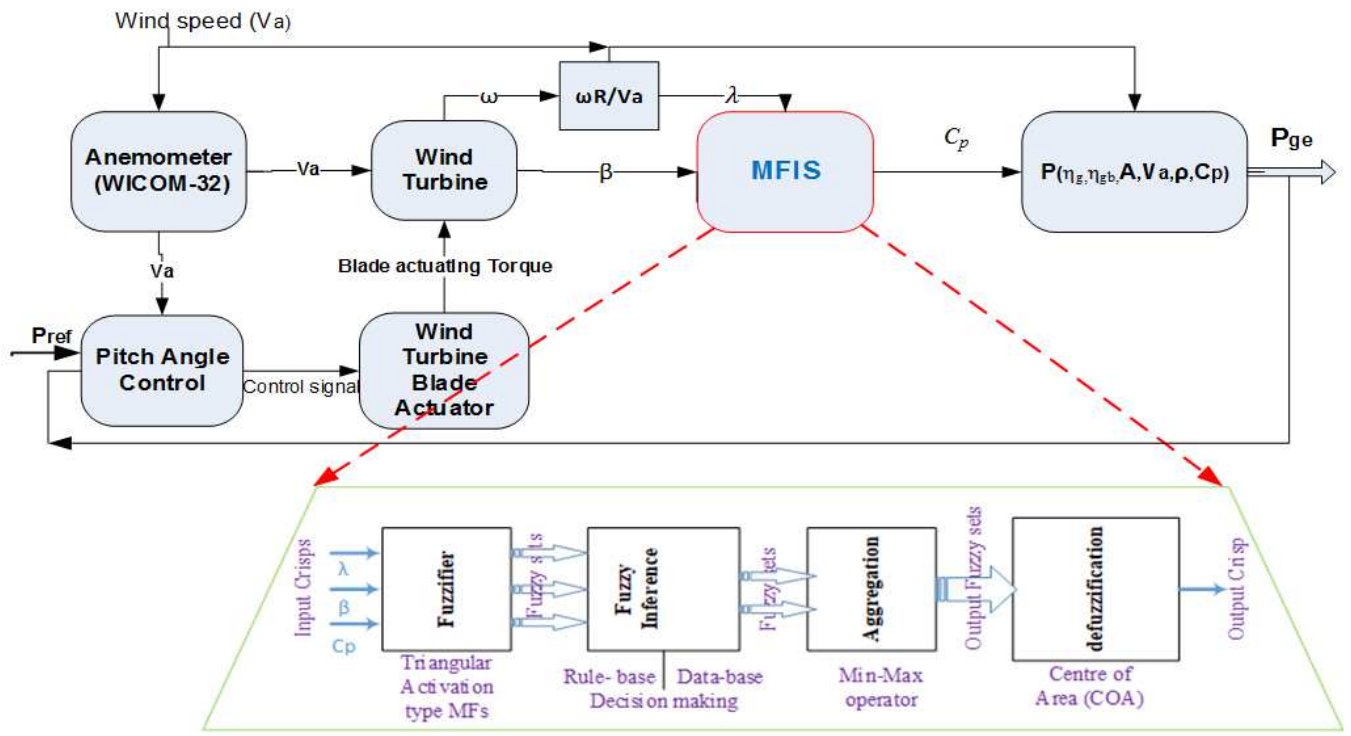

Figure 4. MFIS based Optimization Scheme to Maximize Output Power of the HAWT.

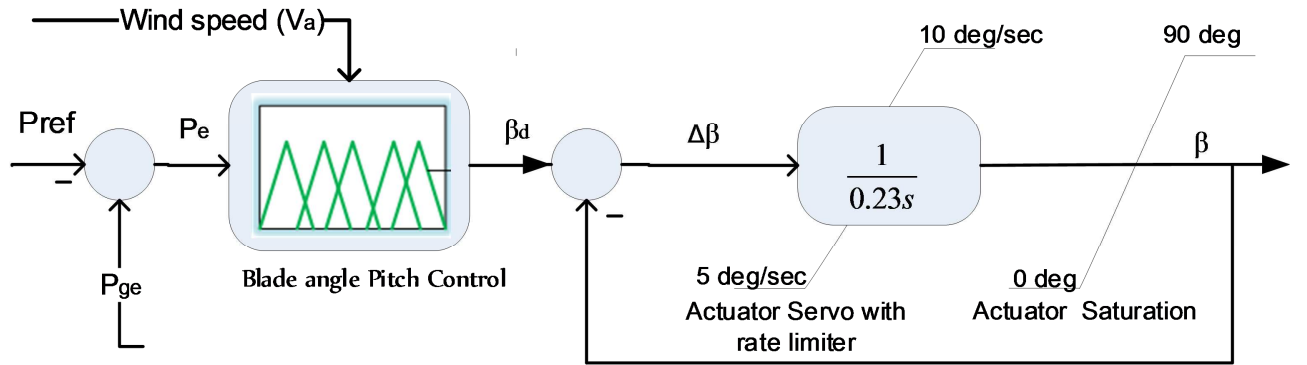

Figure 5. Variable-pitch Actuator with Fuzzy Logic-based Control.

The second stage is the fuzzy inference engine that makes decisions using the fuzzy IF-THEN rules with "AND" or "OR" operators. This block contains the rule-base (IF-THEN $\mathrm{N}$ rules), database (defines membership functions of fuzzy sets), and decision-making (computes inference operation: max- product or max-min). For instance, the fuzzy rule- 1 is

$$
\mathrm{R}^{\mathrm{l}} \text { : If } \lambda \text { is } \lambda_{j}{ }^{\mathrm{l}} \text { AND } \beta \text { is } \beta_{\mathrm{j}}{ }^{\mathrm{l}} \text { THEN } \mathrm{C}_{\mathrm{p}} \text { is } \mathrm{C}_{\mathrm{pj}}{ }^{\mathrm{l}}
$$

Where $\lambda_{j}{ }^{1}$ and $\beta_{j}{ }^{l}$, and $C_{p j}{ }^{1}$ are the fuzzy sets of premises and output consequent at fuzzy rule 1 . Based on the knowledge obtained from Figure 3 and model (3a), the fuzzy sets and rules base is presented in Table 4 and Table 5 .

Table 4. Fuzzy Rule-based Optimization of $C_{p}(\lambda, \beta)$.

\begin{tabular}{|c|c|c|c|c|c|c|}
\hline \multirow{2}{*}{\multicolumn{2}{|c|}{$C_{p}(\lambda, \beta)$}} & \multicolumn{5}{|l|}{$\boldsymbol{\beta}$} \\
\hline & & $\mathbf{Z}$ & $\mathbf{S}$ & M & $\mathbf{L}$ & VL \\
\hline \multirow{6}{*}{$\lambda$} & $Z$ & $\mathrm{Z}$ & $\mathrm{Z}$ & $\mathrm{Z}$ & $\mathrm{Z}$ & $Z$ \\
\hline & $\mathrm{S}$ & $\mathrm{L}$ & $\mathrm{L}$ & $\mathrm{M}$ & $\mathrm{S}$ & $\mathrm{Z}$ \\
\hline & $\mathrm{M}$ & VL & $\mathrm{L}$ & $\mathrm{M}$ & $\mathrm{S}$ & $\mathrm{Z}$ \\
\hline & Z & Z & Z & Z & Z & Z \\
\hline & $\mathrm{L}$ & $\mathrm{S}$ & S & S & $\mathrm{S}$ & Z \\
\hline & VL & Z & Z & Z & Z & Z \\
\hline
\end{tabular}

Where $\mathrm{Z}=$ Zero, $\mathrm{S}=$ Small, $\mathrm{M}=$ Mean, $\mathrm{L}=$ Large, and $\mathrm{VL}$ $=$ Very Large is the fuzzy sets of the crisp inputs and output variables. The pitch angle input to MFIS is adjusted by the pitch actuator controller that is presented in section 4.1.
Table 5. The MFIS IF-THEN Rules to Maximize Wind Power to Mechanical power conversion coefficient $\left(C_{p}\right)$ of SE7715 Wind Turbine.

\begin{tabular}{|c|c|}
\hline Fuzzy Rule No. & $\begin{array}{l}\text { Fuzzy Rules that Relate each fuzzy sets with } \\
\text { Crisps in the Domain }\end{array}$ \\
\hline $\mathrm{R} 1$ & IF $\lambda$ is $Z$ AND $\beta$ is $Z$, THEN $C_{p}$ is $Z$ \\
\hline $\mathrm{R} 2$ & IF $\lambda$ is $Z$ AND $\beta$ is $S$, THEN $C_{p}$ is $Z$ \\
\hline R3 & IF $\lambda$ is $Z$ AND $\beta$ is $M$, THEN $C_{p}$ is $Z$ \\
\hline R4 & IF $\lambda$ is $Z$ AND $\beta$ is $L$, THEN $C_{p}$ is $Z$ \\
\hline R5 & IF $\lambda$ is $Z$ AND $\beta$ is VL, THEN $C_{p}$ is $Z$ \\
\hline R6 & IF $\lambda$ is $\mathrm{S} A N D \beta$ is $Z$, THEN $C_{p}$ is $M$ \\
\hline R7 & IF $\lambda$ is $\mathrm{S} A N D \beta$ is $S$, THEN $C_{p}$ is $M$ \\
\hline $\mathrm{R} 8$ & IF $\lambda$ is $\mathrm{S} A N D \beta$ is $M$, THEN $C_{p}$ is $M$ \\
\hline R9 & IF $\lambda$ is $\mathrm{S} A N D \beta$ is $\mathrm{L}$, THEN $\mathrm{C}_{\mathrm{p}}$ is $\mathrm{S}$ \\
\hline $\mathrm{R} 10$ & IF $\lambda$ is $\mathrm{S} A N D \beta$ is VL, THEN $\mathrm{C}_{\mathrm{p}}$ is $Z$ \\
\hline R11 & IF $\lambda$ is $M A N D \beta$ is $Z$, THEN $C_{p}$ is VL \\
\hline $\mathrm{R} 12$ & IF $\lambda$ is $M$ AND $\beta$ is $S$, THEN $C_{p}$ is $L$ \\
\hline $\mathrm{R} 13$ & IF $\lambda$ is $M A N D \beta$ is $M$, THEN $C_{p}$ is $M$ \\
\hline R14 & IF $\lambda$ is $M A N D \beta$ is $L$, THEN $C_{p}$ is $S$ \\
\hline $\mathrm{R} 15$ & IF $\lambda$ is $M A N D \beta$ is VL, THEN $C_{p}$ is $Z$ \\
\hline $\mathrm{R} 16$ & IF $\lambda$ is $\operatorname{LAND} \beta$ is $Z$, THEN $C_{p}$ is $S$ \\
\hline $\mathrm{R} 17$ & IF $\lambda$ is $L A N D \beta$ is $S$, THEN $C_{p}$ is $S$ \\
\hline $\mathrm{R} 18$ & IF $\lambda$ is $\operatorname{LAND} \beta$ is $M$, THEN $C_{p}$ is $S$ \\
\hline R19 & IF $\lambda$ is $L A N D \beta$ is $L$, THEN $C_{p}$ is $S$ \\
\hline R20 & IF $\lambda$ is $\mathrm{LAND} \beta$ is VL, THEN $\mathrm{C}_{\mathrm{p}}$ is $\mathrm{Z}$ \\
\hline $\mathrm{R} 21$ & IF $\lambda$ is VL AND $\beta$ is $Z$, THEN $C_{p}$ is $Z$ \\
\hline $\mathrm{R} 22$ & IF $\lambda$ is VL AND $\beta$ is $S$, THEN $C_{p}$ is $Z$ \\
\hline R23 & IF $\lambda$ is VL AND $\beta$ is $M$, THEN $C_{p}$ is $Z$ \\
\hline R24 & IF $\lambda$ is VL AND $\beta$ is $L$, THEN $C_{p}$ is $Z$ \\
\hline $\mathrm{R} 25$ & IF $\lambda$ is VL AND $\beta$ is VL, THEN $C_{p}$ is $Z$ \\
\hline
\end{tabular}


The fuzzy MF of the knowledge described by (8) is implicated as

$$
\mu\left(R^{l}\right): \mu\left(\lambda_{j}{ }^{l} \text { and } \beta_{j}{ }^{l}\right) \rightarrow \mu\left(\mathrm{C}_{\mathrm{pj}}{ }^{l}\right)
$$

Employing the Mandani max-product inference (obtaining new knowledge or rule from the available knowledge or rule) operation on Eq. (9) is

$$
\begin{aligned}
\mu\left(R^{l}\right)= & \max \left\{\mu\left(\lambda_{j}{ }^{l}\right) \text { and } \mu\left(\beta_{j}{ }^{l}\right), \mu\left(C_{p j}{ }^{l}\right)\right\} \\
& =\max \left\{\operatorname{prod}\left(\mu\left(\lambda_{j}{ }^{l}\right) \text { and } \mu\left(\beta_{j}{ }^{l}\right)\right), \mu\left(C_{p j}{ }^{l}\right)\right\} \\
= & \max \left\{\alpha^{l}, \mu\left(C_{p j}{ }^{l}\right)\right\}
\end{aligned}
$$

Where the product implication is

$$
\alpha^{l}=\mu\left(\lambda_{j}{ }^{l}\right) \text { and } \mu\left(\beta_{j}{ }^{l}\right)=\mu\left(\lambda_{j}{ }^{l}\right) \cdot \mu\left(\beta_{j}{ }^{l}\right)
$$

The third stage is the aggregation of all rules to produce a single output of the fuzzy system as expressed below.

$$
\mu\left(c_{p}\right)=\operatorname{Agg}\left(\mu\left(R^{1}\right), \mu\left(R^{2}\right), \ldots, \mu\left(R^{L}\right)\right)=\bigcup_{l=1}^{L} \mu\left(R^{l}\right)
$$

The last stage is the defuzzification. The fuzzy numbers are mapped into a crisp number using the fuzzy max-product combination and centroid of area (COA) defuzzification method.

$$
{\widehat{C_{p}}}^{d}=\frac{\sum_{l=1}^{L} \alpha^{l} \cdot C_{p j}{ }^{l}}{\sum_{l=1}^{L} \alpha^{l}}
$$

\subsubsection{Fuzzy Membership Functions Parameters Optimization}

Before $C_{p}$ optimization, the parameters of MFs of fuzzified input and output of the MFIS are optimally updated via the following training procedure. For $\mathrm{d}=1,2 \ldots \mathrm{D}$ is the number of paired training data $\left[\lambda, \beta: C_{p}\right]=\left[\lambda^{\mathrm{d}}, \beta^{\mathrm{d}}: \mathrm{C}_{\mathrm{p}}{ }^{\mathrm{d}}\right]$ where $\lambda^{\mathrm{d}} \in \lambda_{\mathrm{FS}}$ $=\left[\begin{array}{ll}0 & 12\end{array}\right], \beta^{\mathrm{d}} \in \beta_{\mathrm{FS}}=\left[\begin{array}{ll}0^{0} & 30^{\circ}\end{array}\right]$ and $\mathrm{C}_{\mathrm{p}}^{\mathrm{d}} \in \mathrm{C}_{\mathrm{p}-\mathrm{FS}}=\left[\begin{array}{ll}0 & 0.593\end{array}\right]$ where $\lambda_{\mathrm{FS}}, \beta_{\mathrm{FS}}$ and $\mathrm{C}_{\mathrm{p}-\mathrm{FS}}$ respectively represent the subsets of crisps $\lambda, \beta$ and $\mathrm{C}_{\mathrm{p}}$. These are the aerodynamic limits of a typical horizontal axis wind turbine with three blades to

\begin{tabular}{|c|c|c|c|}
\hline $\begin{array}{l}\text { Linguistic variable } \\
\text { name }\end{array}$ & $\begin{array}{l}\text { Equivalent } \\
\text { fuzzy Set }\end{array}$ & $\begin{array}{l}\text { The domain of the } \\
\text { crisps }\end{array}$ & Membership functions and their optimum parameters \\
\hline \multirow{5}{*}{$\begin{array}{l}\text { Wind Turbine blade tip } \\
\text { Speed Ratio }(\lambda) \text { in rad }\end{array}$} & $Z=$ Zero & {$\left[\begin{array}{ll}0 & 3\end{array}\right]$} & $\mu_{\lambda_{Z}}(\lambda)=\left\{\begin{array}{l}0, \lambda<0 \& \lambda>\sigma_{\lambda 1}{ }^{l}=3 \\
1-\frac{\lambda}{3}, 0 \leq \lambda \leq \sigma_{\lambda 1}{ }^{l}=3\end{array}\right.$ \\
\hline & $\mathrm{S}=$ Small & {$\left[\begin{array}{ll}0 & 6\end{array}\right]$} & $\mu_{\lambda_{S}}(\lambda)=\left\{\begin{array}{c}1-\frac{\mid}{\sigma_{\lambda 1}^{l} \mid},\left|\lambda-\sigma_{\lambda 1^{l}}{ }^{l}\right| \leq \sigma_{\lambda 1}^{l}=3 \\
0, \text { elsewhere }\end{array}\right.$ \\
\hline & $\mathrm{M}=$ Mean & [3 9] & $\mu_{\lambda_{M}}(\lambda)=\left\{\begin{array}{c}1-\frac{\left|{ }^{\lambda-\sigma} \lambda 2\right|}{\sigma_{\lambda 2}^{l} / 2},\left|\lambda-\sigma_{\lambda 2}{ }^{l}\right| \leq \sigma_{\lambda 2}{ }^{l}=6 \\
0, \text { elsewhere }\end{array}\right.$ \\
\hline & $\mathrm{L}=$ Large & {$\left[\begin{array}{ll}6 & 12\end{array}\right]$} & $\mu_{\lambda_{L}}(\zeta)=\left\{\begin{array}{c}1-\frac{|\lambda|}{\sigma_{\lambda 3^{l}}{ }^{l} / 3},\left|\lambda-\sigma_{\lambda 3^{l}}\right| \leq \sigma_{\lambda 3^{l}}=9 \\
0, \text { elsewhere }\end{array}\right.$ \\
\hline & $\begin{array}{l}\mathrm{VL}=\text { Very } \\
\text { Large }\end{array}$ & {$\left[\begin{array}{ll}9 & 12\end{array}\right]$} & $\mu_{\lambda_{V L}}(\lambda)=\left\{\begin{array}{c}1-\frac{\left|{ }^{\lambda-\sigma \lambda 4}\right|}{\sigma_{\lambda 4}{ }^{l} / 4},\left|\lambda-\sigma_{\lambda 4}{ }^{l}\right| \leq \sigma_{\lambda 4}{ }^{l}=12 \\
0, \text { elsewhere }\end{array}\right.$ \\
\hline
\end{tabular}
harvest better energy from the wind. At any iteration number $\mathrm{k}=1,2, \ldots, \mathrm{K}$, substituting (11) into (13), the crisp output is expressed as in (14).

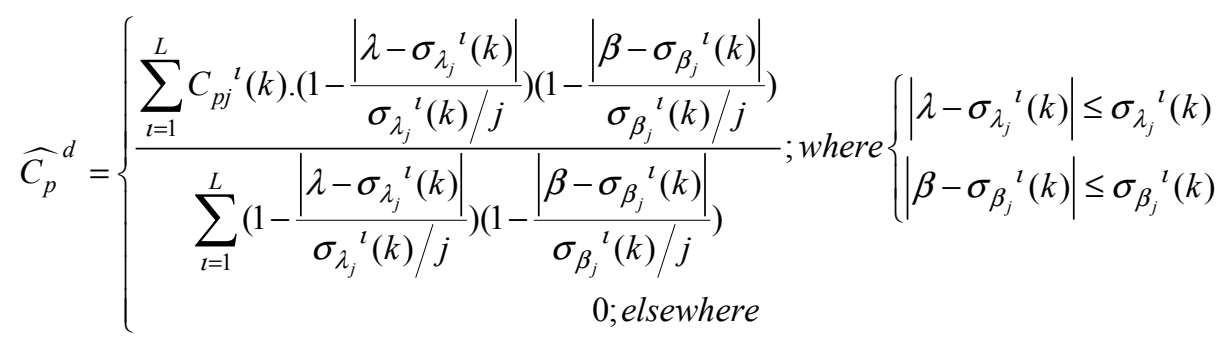

Table 6. MFIS Membership Functions of the Wind Turbine Blade Tip Speed Ratio, Blade Pitch Angle, the Power Conversion Coefficient. 


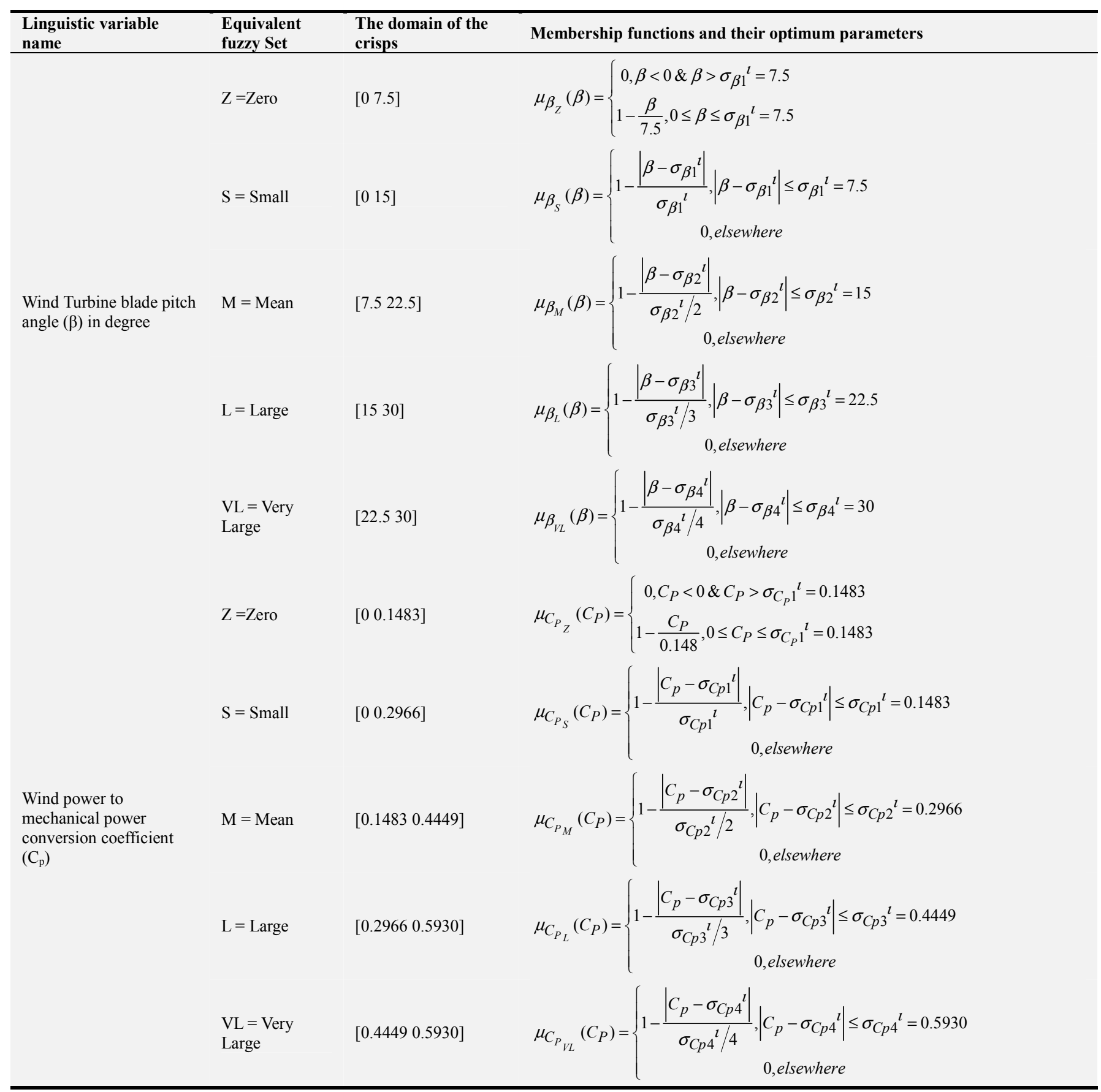

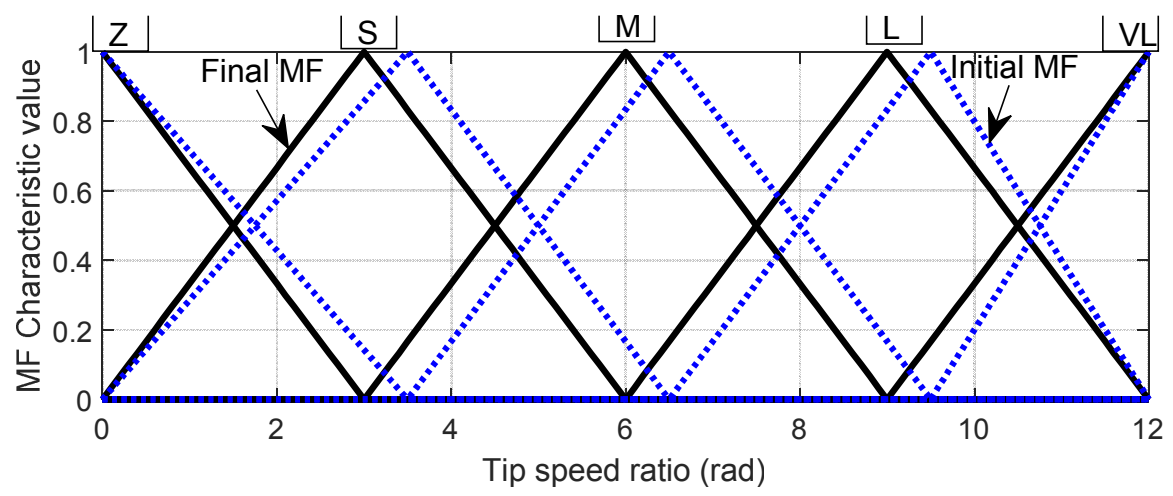

(a) 


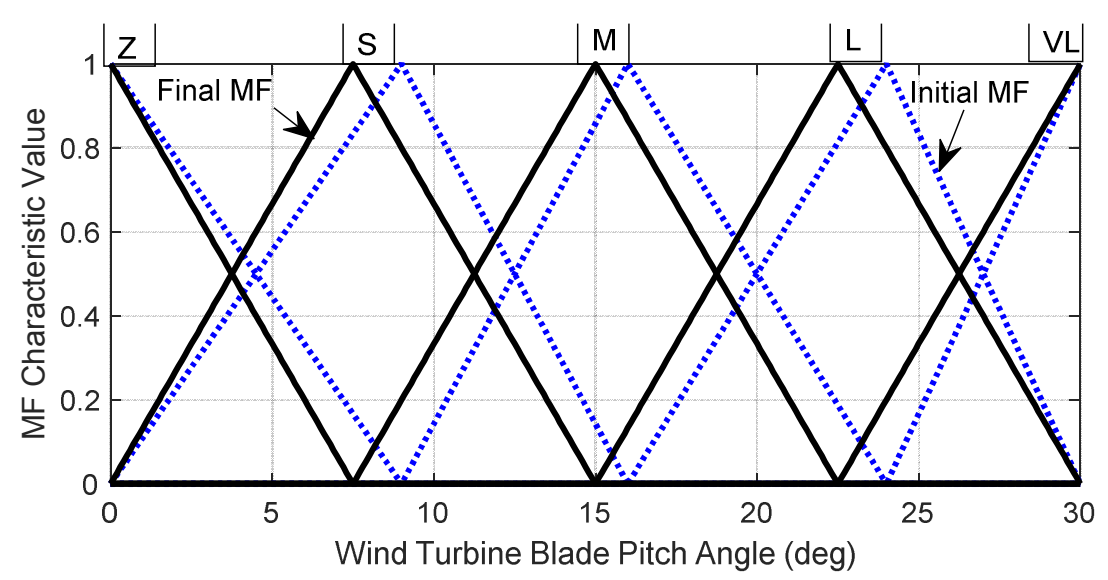

(b)

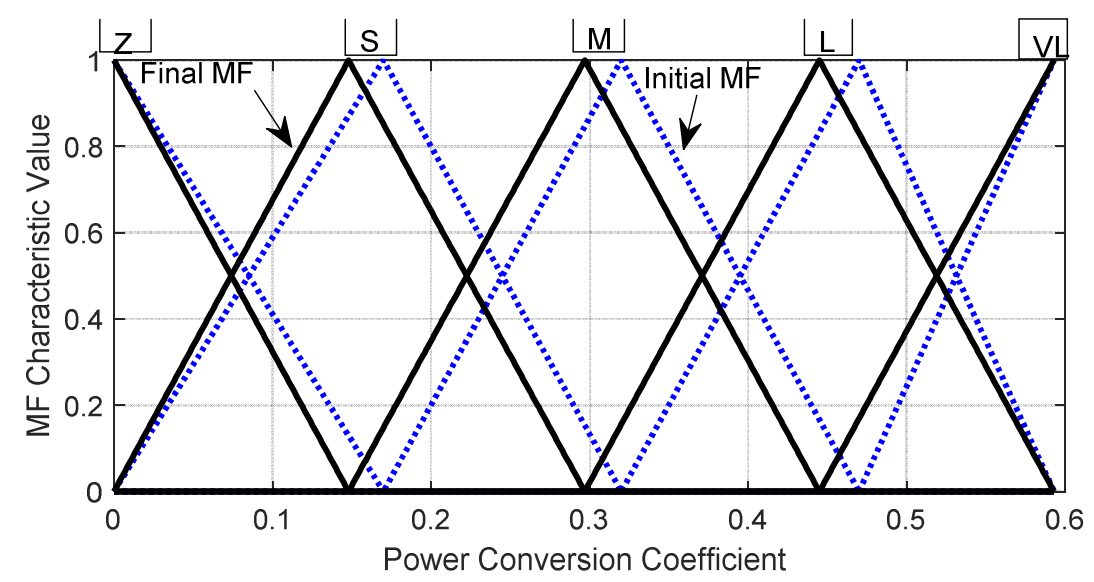

(c)

Figure 6. Graphical presentation of Triangular Membership Functions of the Wind Turbine: (a) Blade Tip Speed Ratio, (b) Blade Pitch Angle, (c) Power Conversion Coefficient.

Graphical demonstration of triangular MFs of $\lambda, \beta$, and $C_{p}$ of a wind turbine are presented in Figure 6 . These are plotted for the triangular relations represented in Table 6. As indicated in this figure, the tip speed ratio of value between $0-12$, the pitch angle of value between 0-30 degrees and the power conversion coefficient ranges between 0 to 0.593 are used.

They are optimally updated by employing the gradient descent method $[39,40]$ through minimization of the square of the norm of error $\left(\varepsilon^{d}\right)$ between the expected crisp output $\left(\hat{C}_{p}^{d}\right)$ of fuzzy logic and the desired value $\left(C_{p}^{d}\right)$, which is expressed as

$$
\left\|\varepsilon^{d}\right\|^{2}=\frac{1}{2} \sum_{d=1}^{D}\left({\widehat{C_{p}}}^{d}-C_{p}^{d}\right)^{2}
$$

The parameters of MF are updated as

$$
\Phi_{j}^{l}(k+1)=\Phi_{j}^{l}(k)-\eta \cdot \frac{\partial \widehat{C}_{p}^{d}}{\partial \Phi_{j}^{l}} \mid \Phi_{j}^{l}(k)
$$

Where $\eta$ is the learning rate and at an initial iteration $\eta \leq$ 1 and becomes 0 at the end of iteration for fast convergence of training [41]. To simplify the computation of training, the numerator and denominator of fuzzy logic output crisp equation (14) is separately expressed as

$$
\gamma=\sum_{l=1}^{L} C_{p j}{ }^{l} \cdot \alpha^{l} \text { and } \xi=\sum_{l=1}^{L} \alpha^{l}
$$

Using the chain differential rule, the change in any premise parameter is carried as follows.

$$
\frac{\partial \widehat{C}_{p}{ }^{d}}{\partial \Phi_{j}^{l}(k)}=\frac{\partial \varepsilon}{\partial \widehat{C}_{p}{ }^{d}} \frac{\partial \widehat{C}_{p}{ }^{d}}{\partial \gamma} \frac{\partial \gamma}{\partial \Phi_{j}^{l}(k)}
$$

Where

$$
\begin{gathered}
\frac{\partial \varepsilon^{d}}{\partial \hat{C}_{p}^{d}}=\left(\widehat{C}_{p}{ }^{d}-C_{p}{ }^{d}\right)=\varepsilon^{d} \\
\frac{\partial{\widehat{C_{p}}}^{d}}{\partial \gamma}=\frac{1}{\xi}=\frac{1}{\sum_{l=1}^{L} \alpha^{l}}=\frac{1}{\sum_{l=1}^{L} \mu\left(\lambda_{j}{ }^{l}\right) \mu\left(\beta_{j}{ }^{l}\right)}
\end{gathered}
$$




$$
\frac{\partial \gamma}{\partial \Phi^{l}{ }_{j}(k)}=\left[\frac{\partial \gamma}{\partial{\sigma_{\lambda_{j}}{ }^{l}(k)}}, \frac{\partial \gamma}{\partial{\sigma_{\beta_{j}}{ }^{l}(k)}^{l}}, \frac{\partial \gamma}{\partial C_{p j}{ }^{l}(k)}\right]^{T}
$$

Where

$$
\frac{\partial \gamma}{\partial \sigma_{\lambda_{j}}{ }^{l}(k)}=\left\{\begin{array}{l}
C_{p j}{ }^{l}(k) \mu_{\beta^{l}}\left(\beta^{d}\right) \frac{\lambda^{d} / j}{\left(\sigma_{\lambda_{j}}{ }^{l}(k) / j\right)^{2}} ; \lambda^{d}>\sigma_{\lambda_{j}}{ }^{l}(k) \\
-C_{p j}{ }^{l}(k) \mu_{\beta^{l}}\left(\beta^{d}\right) \frac{\lambda^{d} / j}{\left(\sigma_{\lambda_{j}}{ }^{l}(k) / j\right)^{2}} ; \lambda^{d} \leq \sigma_{\lambda_{j}}{ }^{l}(k)
\end{array}\right.
$$

For $\beta^{d} \leq{\sigma_{\beta_{j}}}^{l}(k)$ and $C_{p}{ }^{d} \leq C_{p j}{ }^{l}(k)$

$$
\frac{\partial \gamma}{\partial \sigma_{\beta_{j}}{ }^{l}(k)}=\left\{\begin{array}{l}
\left.C_{p j}{ }^{l}(k) \mu_{\lambda^{l}}\left(\lambda^{d}\right) \frac{\beta^{d} / j}{\left(\sigma_{\beta_{j}}{ }^{l}(k) / j\right)^{2}} ; \beta^{d}>{\sigma_{\beta_{j}}{ }^{l}(k)} C_{p j}{ }^{l}(k) \mu_{\lambda^{l}}{ }^{l} \lambda^{d}\right) \frac{\beta^{d} / j}{\left(\sigma_{\beta_{j}}{ }^{l}(k) / j\right)^{2}} ; \beta^{d} \leq{\sigma_{\beta_{j}}{ }^{l}(k)}{ }^{2}(k)
\end{array}\right.
$$

For $\lambda^{d} \leq \sigma_{\lambda_{j}}{ }^{l}(k)$ and $C_{p}{ }^{d} \leq C_{p j}{ }^{l}(k)$

$$
\frac{\partial \gamma}{\partial C_{p j}{ }^{l}(k)}=\mu_{\lambda^{l}}\left(\lambda^{d}\right) \mu_{\beta^{t}}\left(\beta^{d}\right)
$$

Equation (16) is rewritten as in equation (22) considering $\sigma_{\lambda j}{ }^{\prime}(k) \neq 0, \sigma_{\beta j}{ }^{\prime}(k) \neq 0$ and $\mathrm{j} \neq 0$.

The parameters of the first MF $(j=0)$ of each crisps input and output of fuzzy are based on the center parameters of the second MFs $(j=1)$ as depicted in Table 6 . To compute parameters of the second MFs using Eq. (22), first, inputs and corresponding expected output data in the fuzzy set, the number of MFs of each input and output and initial value of parameters of MFs is correctly specified as indicated in Table 7. For better accuracy, $50 \%$ overlap of MFs at an initial iteration of parameters of the second MF with

$$
\Phi_{1}^{l}(0)=\left[\sigma_{\lambda_{1}}{ }^{l}(0), \sigma_{\beta_{1}}{ }^{l}(0), C_{p 1}{ }^{l}(0)\right]^{T}=[3.5,9,0.17]^{T}
$$

and $\eta=0.01$ are randomly selected. Using these values and the data in Table 7, optimal $\Phi_{1}^{l}(k)$ is computed at k-iteration. For instance, the first iteration $\sigma_{\lambda 1}{ }^{1}(1)$ is computed using (23). In the same way, $\sigma_{\beta 1}{ }^{\prime}(1)$ and $C_{p 1}{ }^{\prime}(1)$ are computed. At $\mathrm{k}=2$, the parameters of the second MF of each crisp are $\Phi_{1}{ }^{1}(2)=$ $\left[\sigma_{\lambda 1}{ }^{1}(2), \sigma_{\beta 1}{ }^{1}(2), C_{p 1}{ }^{1}(2)\right]^{\mathrm{T}}=[3,7.5,0.1483]^{\mathrm{T}}$.

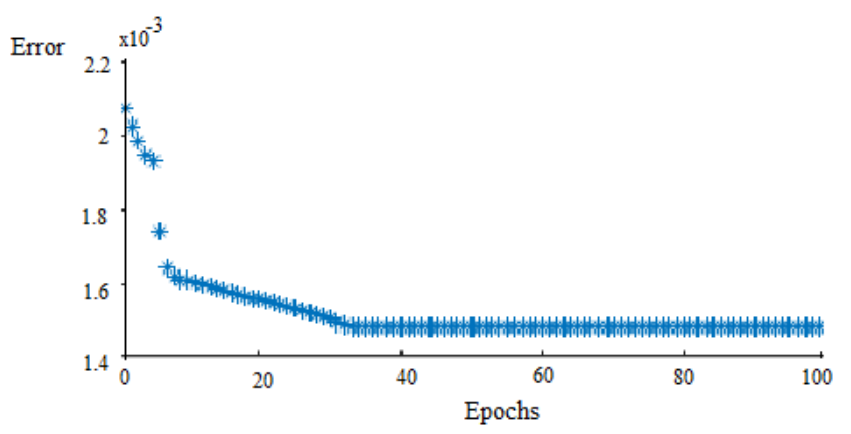

Figure 7. Error Convergence using Gradient DescentTraining Method.

As seen in Figure 7, the convergence is reached within the first two iterations under the application of the mentioned learning technique for MFs parameters optimization. The validation of the training result is evaluated by using the root mean squared error of the output in (13); in which the minimum training error of the membership function by the aforementioned method is 0.001485 as in Figure 7.

At any $k$-iteration, the parameters of the next MFs $(j=2,3$, 4) are procedurally computed as $\Phi_{j}^{l}(k)=j . \Phi_{1}^{l}(k)$, that is

$$
\begin{gathered}
\Phi_{2}^{l}(k)=\left[\begin{array}{c}
\sigma_{\lambda_{2}}{ }^{l}(k) \\
\sigma_{\beta_{2}}{ }^{l}(k) \\
C_{p 2}{ }^{l}(k)
\end{array}\right]=2\left[\begin{array}{c}
\sigma_{\lambda_{1}}{ }^{l}(k) \\
\sigma_{\beta_{1}}{ }^{l}(k) \\
C_{p 1}{ }^{l}(k)
\end{array}\right] \\
\Phi_{3}^{l}(k)=\left[\begin{array}{c}
\sigma_{\lambda_{2}}{ }^{l}(k) \\
\sigma_{\beta_{2}}{ }^{l}(k) \\
C_{p 2}{ }^{l}(k)
\end{array}\right]=3\left[\begin{array}{c}
\sigma_{\lambda_{1}}{ }^{l}(k) \\
\sigma_{\beta_{1}}{ }^{l}(k) \\
C_{p 1}{ }^{l}(k)
\end{array}\right]
\end{gathered}
$$




$$
\Phi_{4}^{l}(k)=\left[\begin{array}{c}
\sigma_{\lambda_{4}}{ }^{l}(k) \\
\sigma_{\beta_{4}}{ }^{l}(k) \\
C_{p 4}{ }^{l}(k)
\end{array}\right]=4\left[\begin{array}{c}
\sigma_{\lambda_{1}}{ }^{l}(k) \\
\sigma_{\beta_{1}}{ }^{l}(k) \\
C_{p 1}{ }^{l}(k)
\end{array}\right]
$$

Table 7. Training data to iteratively update parameters of the second MFs ( $j$ $=1)$ of $\lambda, \beta$ and $C_{p}$.

\begin{tabular}{lllll}
\hline$\lambda^{\boldsymbol{d}}$ & $\boldsymbol{\beta}^{\boldsymbol{d}}$ & $\boldsymbol{C}_{\boldsymbol{p}} \boldsymbol{d}^{\boldsymbol{1}}$ & $\hat{\boldsymbol{C}}_{\boldsymbol{p}} \boldsymbol{d}^{\mathrm{d}}$ & $\widehat{\boldsymbol{C}}_{\boldsymbol{p}}{ }^{\boldsymbol{d}}-\boldsymbol{C}_{\boldsymbol{p}}{ }^{\boldsymbol{d}}$ \\
\hline 0 & 0 & 0 & 0 & 0 \\
0.2 & 0.5 & 0.0099 & 0.0097 & -0.0002 \\
0.4 & 1.0 & 0.0198 & 0.0150 & -0.0018 \\
0.6 & 1.5 & 0.0297 & 0.0270 & -0.0027 \\
0.8 & 2.0 & 0.0396 & 0.0390 & -0.0006 \\
1.0 & 2.5 & 0.0494 & 0.0492 & -0.0002 \\
1.2 & 3.0 & 0.0593 & 0.0545 & -0.0048 \\
1.4 & 3.5 & 0.0692 & 0.0692 & 0 \\
1.6 & 4.0 & 0.0791 & 0.0792 & 0.0001 \\
1.8 & 4.5 & 0.0890 & 0.0891 & 0.0001 \\
2.0 & 5.0 & 0.0989 & 0.0987 & -0.0002 \\
2.2 & 5.5 & 0.1088 & 0.1085 & -0.0003 \\
2.4 & 6.0 & 0.1187 & 0.1188 & 0.0001 \\
2.6 & 6.5 & 0.1286 & 0.1289 & 0.0003 \\
2.8 & 7.0 & 0.1385 & 0.1384 & -0.0001 \\
3.0 & 7.5 & 0.1484 & 0.1485 & $1 \mathrm{E}-04$ \\
3.2 & 8.0 & 0.1582 & 0.1582 & 0 \\
3.4 & 8.5 & 0.1681 & 0.1681 & 0 \\
3.6 & 9.0 & 0.1780 & 0.178 & 0 \\
3.8 & 9.5 & 0.1879 & 0.1875 & -0.0004 \\
4.0 & 10.0 & 0.1978 & 0.1977 & -0.0001 \\
4.2 & 10.5 & 0.2077 & 0.2074 & -0.0003 \\
4.4 & 11.0 & 0.2176 & 0.2170 & -0.0006 \\
4.6 & 11.5 & 0.2275 & 0.2278 & 0.0003 \\
4.8 & 12.0 & 0.2374 & 0.2377 & 0.0003 \\
5. & 2.5 & 0.2473 & 0.2474 & 0.0001 \\
5.2 & 13.0 & 0.2571 & 0.2572 & $1 \mathrm{E}-04$ \\
5.4 & 13.5 & 0.2670 & 0.2671 & $1 \mathrm{E}-04$ \\
5.6 & 14.0 & 0.2769 & 0.277 & 0.0001 \\
5.8 & 14.5 & 0.2868 & 0.2862 & -0.0006 \\
6.0 & 15.0 & 0.2966 & 0.2968 & 0.0002 \\
\hline & & & & \\
\hline
\end{tabular}

\subsubsection{Computational Implementation of $C_{p}$ Optimization}

There are a total of fifteen (i.e. $3 \times 5$ ) discrete fuzzy sets of the tip speed ratio, the pitch angle, and the power conversion coefficient which are analytically computed from the optimally generated MFs in Table 6. Using these MFs the discrete fuzzy sets of the inputs-output relations are made ready to employ MFIS as depicted in equations (25) - (27). The discrete fuzzy sets defined over the universe of discourse of the blade tip speed ratio $(\lambda)$ are

$$
\left\{\begin{array}{l}
\mu_{\lambda_{Z}}(\lambda)=\{(1,0),(0.667,1),(0.333,2),(0,3)\} \\
\mu_{\lambda_{S}}(\lambda)=\left\{\begin{array}{c}
(0,0),(0.333,1),(0.667,2), \\
(1,3),(0.667,4),(0.333,5),(0,6)
\end{array}\right\} \\
\mu_{\lambda_{M}}(\lambda)=\left\{\begin{array}{c}
(0,3),(0.333,4),(0.667,5),(1,6), \\
(0.91,6.27),(0.667,7),(0.333,8),(0,9)
\end{array}\right\} \\
\mu_{\lambda_{L}}(\lambda)=\left\{\begin{array}{c}
(0,6),(0.09,6.27),(0.333,7),(0.667,8), \\
(1,9),(0.667,10),(0.333,11),(0,12)
\end{array}\right\} \\
\mu_{\lambda_{V L}}(\lambda)=\{(0,9),(0.333,10),(0.667,11),(1,12)\}
\end{array}\right.
$$

The discrete fuzzy sets defined over the universe of discourse of the blade pitch angle $(\beta)$ are

$$
\begin{aligned}
\mu_{\beta_{Z}}(\beta)=\left\{\begin{array}{c}
(1,0),(0.867,1),(0.733,2),(0.6,3),(0.467,4), \\
(0.333,5),(0.2,6),(0.067,7),(0,7.5)
\end{array}\right\} & \left\{\begin{array}{c}
(0,0),(0.133,1),(0.267,2),(0.4,3),(0.533,4), \\
(0.667,5),(0.8,6),(0.933,7),(1,7.5),(0.933,8), \\
(0.8,9),(0.667,10),(0.533,11),(0.4,12), \\
(0.267,13),(0.133,14),(0,15)
\end{array}\right\} \\
\mu_{\beta_{S}}(\beta) & \left\{\begin{array}{c}
(0,7.5),(0.067,8),(0.2,9),(0.333,10),(0.467,11), \\
(0.6,12),(0.733,13),(0.867,14),(1,15), \\
(0.867,16),(0.733,17),(0.6,18),(0.467,19), \\
(0.333,20),(0.2,21),(0.067,22),(0,22.5)
\end{array}\right\} \\
\mu_{\beta_{M}}(\beta)=\left\{\begin{array}{c}
(0,15),(0.133,16),(0.267,17),(0.4,18),(0.533,19), \\
(0.667,20),(0.8,21),(0.933,22),(1,22.5), \\
(0.933,23),(0.8,24),(0.667,25),(0.533,26), \\
(0.4,27),(0.267,28),(0.133,29),(0,30)
\end{array}\right\} & \left\{\begin{array}{c}
(0,22.5),(0.067,23),(0.2,24), \\
(0.333,25),(0.467,26),(0.6,27), \\
(0.733,28),(0.867,29),(1,30)
\end{array}\right\}
\end{aligned}
$$

The discrete fuzzy sets defined over the universe of discourse of the power conversion coefficient $\left(\mathrm{C}_{\mathrm{p}}\right)$ are

$$
\begin{aligned}
& \int \mu_{C_{P_{Z}}}\left(C_{P}\right)=\{(1,0),(0.662,0.05),(0.324,0.1),(0,0.148)\} \\
& \mu_{C_{P_{S}}}\left(C_{p}\right)=\left\{\begin{array}{c}
(0,0),(0.338,0.05), \\
(0.676,0.1),(1,0.148),(0.986,0.15), \\
(0.649,0.2),(0.311,0.25),(0,0.297)
\end{array}\right\} \\
& \left\{\mu_{C_{P_{M}}}\left(C_{p}\right)=\left\{\begin{array}{l}
(0,0.148),(0.0 .14,0.15),(0.351,0.2), \\
(0.689,0.25),(1,0.297),(0.973,0.3), \\
(0.635,0.35),(0.297,0.4),(0,0.445)
\end{array}\right\}\right. \\
& \mu_{C_{P_{L}}}\left(C_{p}\right)=\left\{\begin{array}{l}
(0,0.297),(0.037,0.3),(0.365,0.35), \\
(0.703,0.4),(1,0.445),(0.959,0.45), \\
(0.622,0.5),(0.284,0.55),(0,0.593)
\end{array}\right\} \\
& \mu_{C_{P_{V L}}}\left(C_{P}\right)=\left\{\begin{array}{c}
(0,0.445),(0.041,0.45), \\
(0.378,0.5),(0.716,0.55),(1,0.593)
\end{array}\right\}
\end{aligned}
$$

Using the discrete fuzzy sets, computation of the optimum power conversion coefficient $\left(\mathrm{C}_{\mathrm{p}}\right)$ for any size of a wind turbine is carried here. The fuzzy logic crisp output $\mathrm{C}_{\mathrm{p}}$ should be optimal; hence the power capturing by wind turbine from the wind would be optimal even for lower wind speed. As depicted by (2), the tip speed ratio is related to both the wind speed and turbine rotor speed. As wind speed increases the rotor speed too. The rotor speed can be maintained constant by pitch regulator and hence tip speed ratio too. To implement the MFIS optimization tool for $\mathrm{C}_{\mathrm{p}}$, three samples are considered. These are in a lower wind speed region (partial load operation), around the rated wind speed, and in a higher wind speed region (full load operation) cases. For the first case, the rotor speed could be controlled to maintain $\lambda$ at the optimal value of 6.268 and the $\beta$ is maintained at $0^{0}$. 
These have fuzzy rules in their domains [3 9 ] $]$ and $\left[\begin{array}{lll}0^{0} & 7.5^{\circ}\end{array}\right]$ respectively. That is, from Table 5 and Table 6 , the membership functions, and the fuzzy rules that have the crisp in the specified domain are defined by R11 and R12 of the MFIS rules. The computation of $\mathrm{C}_{\mathrm{p}}$ is depicted in the following steps.

Step 1. The individual rule-based implication that is the Mamdani fuzzy min implication yields a resultant output fuzzy set for each activated rules are

$$
\text { R11: IF } \lambda \text { is } \mu_{\lambda_{M}} \text { AND } \beta \text { is } \mu_{\beta_{Z}} \text {, THEN C is } \mu_{C_{P_{V L}}}
$$$$
\text { R12: IF } \lambda \text { is } \mu_{\lambda_{M}} \text { AND } \beta \text { is } \mu_{\beta_{S}} \text {, THEN C is } \mu_{C_{P_{L}}}
$$

The activation degrees of membership of the antecedent parts of these rules at the given input crisps are computed using the fuzzy sets depicted in (25) and (26).

$$
\left\{\begin{array}{l}
\mu_{R_{11}}\left(6.268,0^{0}\right)=\min \left(\mu_{\lambda_{M}}(6.268), \mu_{\beta_{Z}}\left(0^{0}\right)\right)=\min (0.91,1)=0.91 \\
\mu_{R_{12}}\left(6.268,0^{0}\right)=\min \left(\mu_{\lambda_{M}}(6.268), \mu_{\beta_{S}}\left(0^{0}\right)\right)=\min (0.91,0)=0
\end{array}\right.
$$

Step 2. The inferred fuzzy sets are computed by associating the result in (29) with the consequent in (28) and the fuzzy sets in (27) by employing Mamdani fuzzy product inference for $\mathrm{i}=1,2, \ldots, 5$, and $\mathrm{j}=1,2, \ldots, 9$ as shown in (30).

$$
\left\{\begin{array}{c}
\mu_{R_{11}}\left(6.268,0^{0}, C p_{i}\right)=\left\{\begin{array}{c} 
\\
\operatorname{prod}\left(\mu_{R_{11}}\left(6.268,0^{0}\right), \mu_{C p_{V L}}\right) \\
=\operatorname{prod}\left(0.91, \mu_{C p_{V L}}\right) \\
(0,0.4450), \\
(0.0127,0.45),(0.3440,0.5), \\
(0.6516,0.55),(0.9100,0.593)
\end{array}\right\} \\
\mu_{R_{12}}\left(6.268,0^{0}, C p_{j}\right)=\left\{\begin{array}{r}
\operatorname{prod}\left(\mu_{R_{12}}\left(6.268,0^{0}\right), \mu_{C p_{L}}\right) \\
= \\
(0,0.297),(0,0.3),(0,0.35), \\
(0,0.4),(0,0.445),(0,0.45), \\
(0,0.5),(0,0.55),(0,0.593)
\end{array}\right\}
\end{array}\right\}
$$

Step 3. Aggregation of the two fuzzy sets in (30) is computed to produce single output fuzzy set by Max- operator of fuzzy logic and the result is

$$
\mu_{R_{11-12}}\left(6.268,0^{0}, C p_{j}\right)=\left\{\begin{array}{r}
\max \left(\mu_{R_{11}}\left(6.268,0^{0}, C p_{i}\right), \mu_{R_{12}}\left(6.268,0^{0}, C p_{j}\right)\right. \\
=\left\{\begin{array}{c}
(0,0.297),(0,0.3),(0,0.35),(0,0.4), \\
(0,0.445),(0.0127,0.45),(0.344,0.5), \\
(0.6516,0.55),(0.91,0.593)
\end{array}\right\}
\end{array}\right.
$$

Step 4. The crisp output value of $\mathrm{C}_{\mathrm{p}}$ is computed from (31) using the center of the area (COA) defuzzification type as in (32).

$$
\begin{gathered}
C_{p}\left(6.268,0^{0}\right)=\frac{\sum_{j=1}^{9} \mu_{R_{11-12}}\left(6.268,0^{0}, C_{p_{j}}\right) * C_{p_{j}}}{\sum_{j=1}^{9} \mu_{R_{11-12}}\left(6.268,0^{0}, C_{p_{j}}\right)} \\
=\frac{\left(\begin{array}{l}
(0 * 0.297)+(0 * 0.3)+(0 * 0.35) \\
+(0 * 0.4)+(0 * 0.445)+(0.0127 * 0.45) \\
+(0.344 * 0.5)+(0.6516 * 0.55)+(0.91 * 0.593)
\end{array}\right)}{(0+0+0+0+0+0.0127+0.344+0.6516+0.91)} \\
=0.5608
\end{gathered}
$$

The second case is when the wind speed is around the rated value $(13 \mathrm{~m} / \mathrm{s})$, the blade pitch angle should be increased by a small value to regulate rotor output power to the rated value and secures the wind turbine. Consider for $\beta=$ $8^{0}$ and $\lambda=6$ the $C_{p}$ can be computed by MFIS as follows. These crisp inputs have common fuzzy rules in their [3 9]

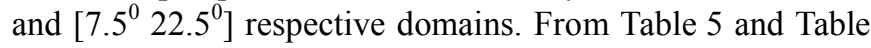
6 , the membership functions and the fuzzy rules that have the crisp in the specified domain are defined by R12 and R13 of the MFIS rules. By repeating the procedure in the first case, the computed $\mathrm{C}_{\mathrm{p}}$ is 0.4360 .

The third case is when the wind speed is greater than the rated value, the blade pitch angle should be increased by moderate value and the tip speed ratio could be smaller to regulate the rotor output power to the rated value. Considering $\beta=25^{\circ}$ and $\lambda=2, C_{p}$ can be computed by 
MFIS as follows. These crisp inputs have fuzzy rules in [0 3 3] and $\left[22.5^{\circ} 30^{0}\right]$ respective domains. From Table 5 and Table 6 , the membership functions and fuzzy rules for these crisp inputs in the specified domain are defined by R4 and R5 of the MFIS rules. Following the steps as in the first case, the computed $\mathrm{C}_{\mathrm{p}}$ is 0.0329 .

\section{Results and Discussion}

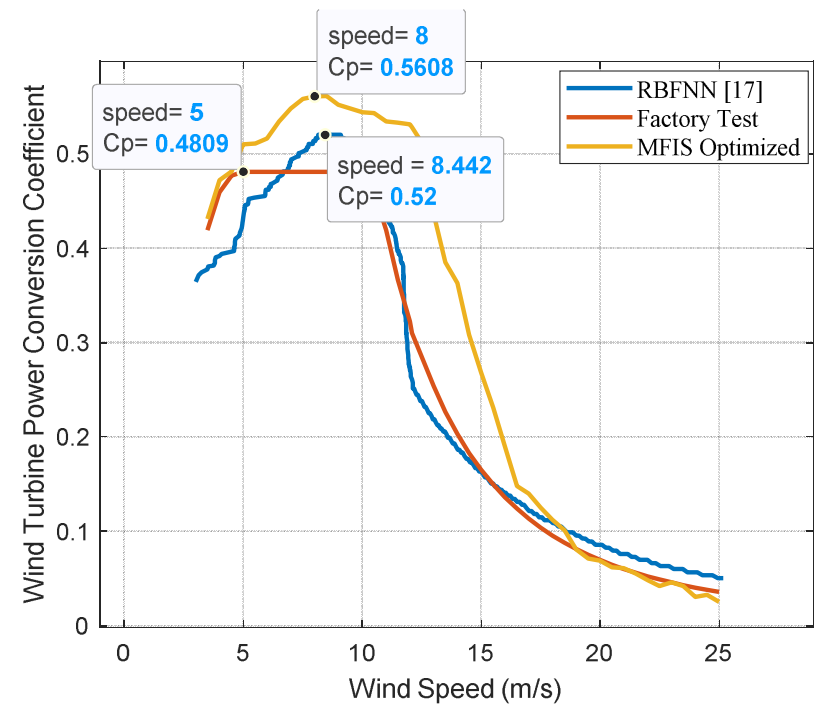

(a)

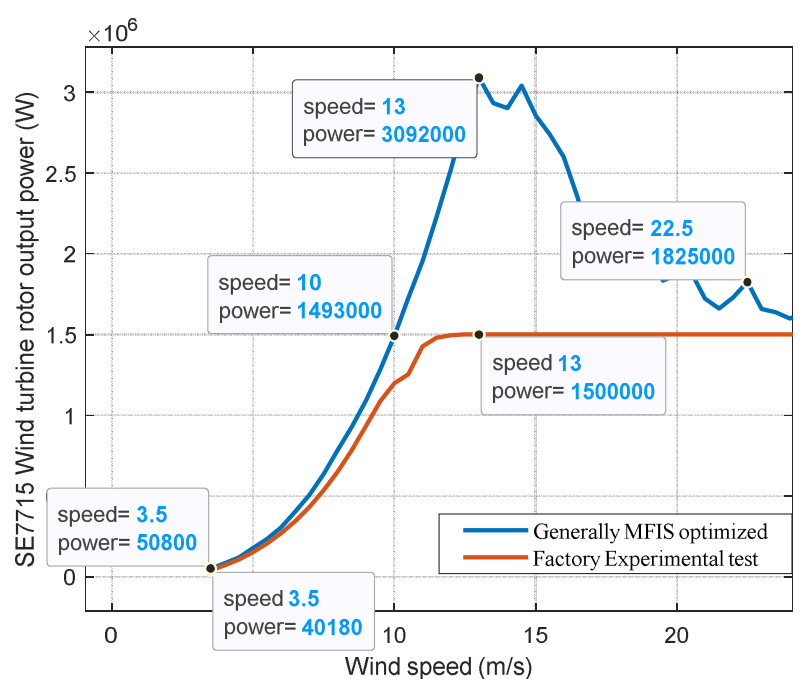

(b)

Figure 8. Comparison of Wind Turbine's (a) Power Conversion Coefficient (b) Output Power of 1.5 MW SE7715.

This study showed 0.5608 is the optimal $\mathrm{C}_{\mathrm{p}}$ and is greater than the values which are presented under the literature review section. The power conversion coefficient was computed repeatedly at different values of the tip speed ratio and blade pitch angle. The result of $C_{P}$ is plotted in comparison with SE7715 wind turbine factory experimental test results as seen in Figure 8 (a). This result indicated the optimized $\mathrm{C}_{\mathrm{p}}$ is equal to 0.5608 at $8 \mathrm{~m} / \mathrm{s}$, but the maximum $\mathrm{C}_{\mathrm{p}}$ from the factory experimental test result of the SE7715 wind turbine is 0.4804 at the same wind speed. This is a $16.74 \%$ improvement in the power conversion coefficient of the SE7715 wind turbine. Also, the MFIS optimized $C_{p}$ is 0.4360 at $13 \mathrm{~m} / \mathrm{s}$ wind speed.

The corresponding $\mathrm{C}_{\mathrm{p}}$ from the factory test result of the SE7715 turbine is 0.2537 . Figure 8 (a) also showed, at a high wind speed of $22.5 \mathrm{~m} / \mathrm{s}$ for instance, $C_{p}$ is reduced to 0.0329 to secure the turbine. These results are used to compute the corresponding output power of the SANY SE7715 wind turbine. Using the specifications of this wind turbine in Table 2 and employing (1), the output power is $175.24 \mathrm{~kW}$ at $5 \mathrm{~m} / \mathrm{s}$ wind speed and computed $\mathrm{C}_{\mathrm{p}}$ of 0.5101 . However, from the experimental data in Figure 8 (b) for the same wind turbine, the output is $151.67 \mathrm{~kW}$ at $5 \mathrm{~m} / \mathrm{s}$ wind speed. The improvement in the output power is $23.57 \mathrm{~kW}$. It is equal to a $15.54 \%$ improvement in output power. When the wind speed is near the rated value, for instance, the optimal computed $\mathrm{C}_{\mathrm{p}}$ is 0.542 at $10.5 \mathrm{~m} / \mathrm{s}$ and hence the rotor output power of the same turbine is $1.725 \mathrm{MW}$. But the rated power is obtained at $12 \mathrm{~m} / \mathrm{s}$ as in Figure 8 (b). This shows the developed optimization method provide rated power before the rated wind speed was reached, indicating that more power can be harvested at a lower wind speed. For some wind speeds below the rated value, the result for power harvesting is present in Table 8 for comparison. Figure 8 (b) shows the simulation of output power as a function of wind speed that was computed using the MFIS in comparison with the factory experimental test data.

At higher wind speed, the simulation result of optimized power by MFIS is beyond the turbine rating. Therefore, the output power regulation to the rated value is a must. This is achieved by the pitch actuator control system that was presented in section 4 . For higher wind speed, the pitch controller generates large pitch command $\left(\beta_{\mathrm{d}}\right)$, and hereafter the pitch actuator acted on the blade to regulate rotor output power to the rated value. The regulated output power at the corresponding pitch angle and the control variables (power error and wind speed) are presented in Figure 9.

Figure 9 portrays the simulation result of (a) the wind speed in the range of cut-in and cut-out speeds of the SE7715 wind turbine, (b) the optimized and regulated output power of the SE7715 wind turbine, (c) the power error between the SE7715 wind turbine output power and the reference power, and (d) blade pitch angle. Figure 9 (a) and (c) are the inputs to the fuzzy logic-based controller of the blade pitch actuator. As indicated in the figure at $18 \mathrm{sec}$ the wind speed is 10.5 $\mathrm{m} / \mathrm{s}$, the output power is $1.5 \mathrm{MW}$ that is attained before the rated wind speed is reached showing improvement in harvested power. The power error is $98 \mathrm{~W}$ and the pitch angle is $0^{\circ}$. When the wind speed is increased beyond 10.5 $\mathrm{m} / \mathrm{s}$, the blade pitch angle regulates the turbine rotor output power to the rated value. For instance, at $22.5 \mathrm{~m} / \mathrm{s}$ wind speed, the computed $\mathrm{C}_{\mathrm{p}}$ is 0.0479 and at $23.5 \mathrm{~m} / \mathrm{s}$ wind speed $\mathrm{C}_{\mathrm{p}}$ is 0.0421 and hence the output power is $1.5 \mathrm{MW}$ and 1.501 MW respectively. 

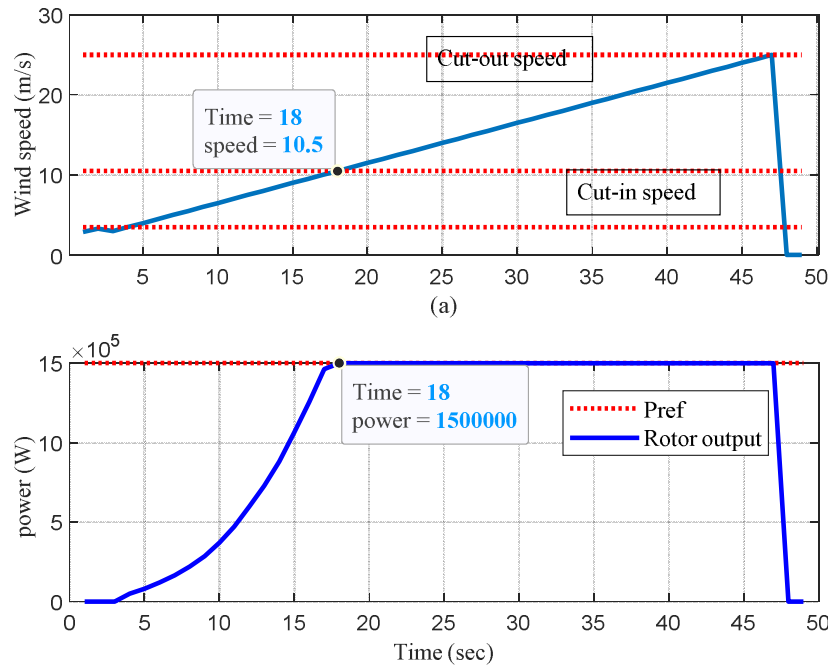

(b)
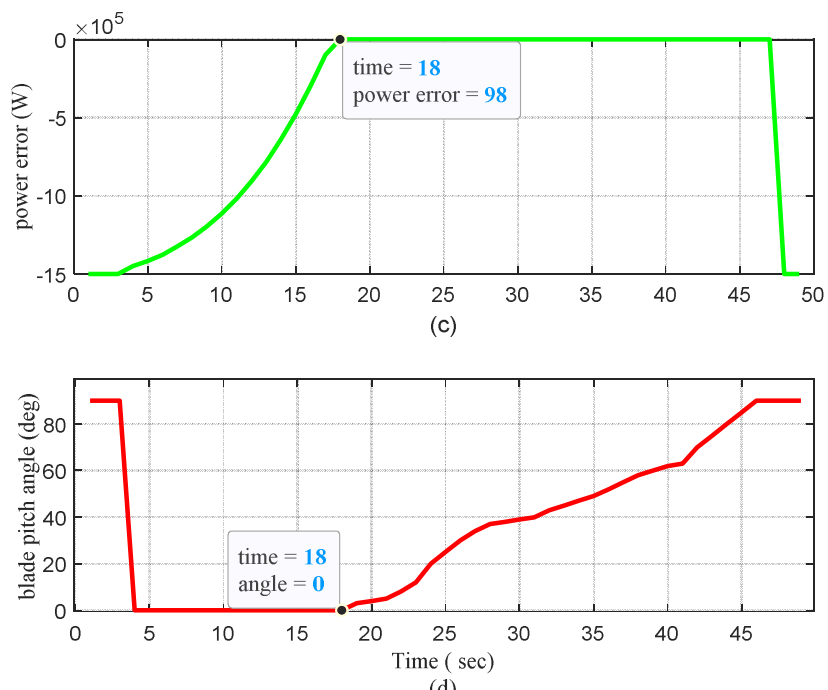

Figure 9. (a) Wind speed, (b) SE7715 WT Rotor Output Power Error, (c) Blade Pitch Angle, and (d) Optimized and Regulated Output Power of SE7715 Wind Turbine.

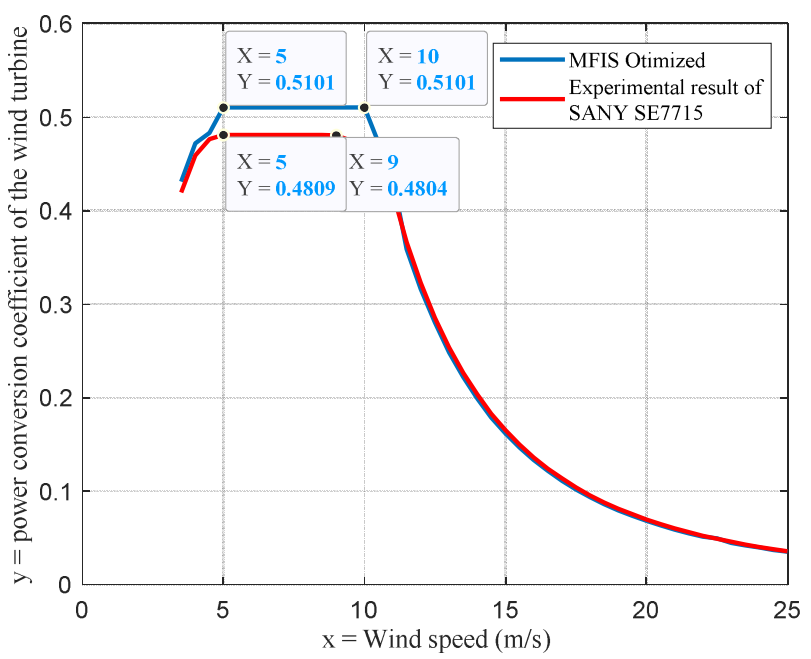

(a)

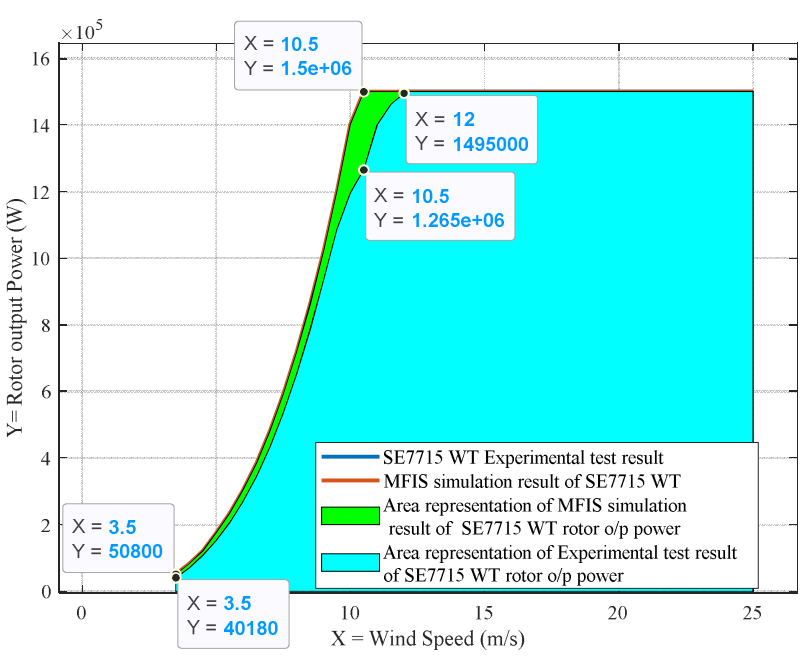

(b)

Figure 10. Comparison of MFIS optimized simulation results with Factory Experimental Test Results (a) Power Conversion Coefficient, (b) output power of $1.5 \mathrm{MW}$ of the SE7715 wind turbine.

Table8. Comparison of MFIS Optimized Power with Output Power SE7715 and Related Recent Work.

\begin{tabular}{|c|c|c|c|c|c|}
\hline \multirow{2}{*}{ Wind speed $(\mathrm{m} / \mathrm{s})$} & \multirow{2}{*}{$\begin{array}{l}\text { RBFNN control based } \\
\text { MPPT }[17](\mathbf{k W})\end{array}$} & \multirow{2}{*}{$\begin{array}{l}\text { Factor Test Sample of } \\
\text { SE7715 }(\mathbf{k W})\end{array}$} & \multirow{2}{*}{$\begin{array}{l}\text { Proposed MFIS based } \\
\text { optimization }(k W)\end{array}$} & \multicolumn{2}{|c|}{ Improved power $(\mathrm{kW})$ compared to } \\
\hline & & & & RBFNN [17] & Factor Test Sample \\
\hline 6 & 307.55 & 268.6 & 346.22 & 38.67 & 37.78 \\
\hline 8 & 729.02 & 651.45 & 785.35 & 56.34 & 133.9 \\
\hline 10 & 1423.86 & 1199.04 & 1492.65 & 68.792 & 293.61 \\
\hline
\end{tabular}

The MFIS optimized power conversion coefficient wind turbine is presented in Figure 10 (a). The MFIS optimized $\mathrm{C}_{\mathrm{p}}$ is maintained constant over the wind speed range of $5-10 \mathrm{~m} / \mathrm{s}$ and hence turbine can have better-regulated rotor speed, whereas the experimental result is constant for the wind speed in the ranges of 5-9 m/s. The MFIS optimized and pitch regulated rotor output power in Figure $9(\mathrm{~b})$ is replotted in Figure 10 (b) for comparison with the factory experimental result. Figure 10 (b) confirmed that the MFIS optimized power is better than the factory experimental result of the SE7715 wind turbine. For instance, at $3.5 \mathrm{~m} / \mathrm{s}$ wind speed, the MFIS optimized power is $50.8 \mathrm{~kW}$ whereas the experimental result is $40.18 \mathrm{~kW}$. That is, with optimized $\mathrm{C}_{\mathrm{p}}$, the turbine can harvest power at a wind speed lower than the cut-in speed $(3.5 \mathrm{~m} / \mathrm{s})$. This showed the proposed MFIS optimization technique is well suitable for wind turbine energy harvesting capacity improvement, and it provided new and interesting results. In summary, the result of the proposed MFIS technique is compared to the results of the most recent researches as shown in Table 8. The proposed MFIS technique for the optimization of wind turbine output power is superior. 


\section{Conclusion}

The method used for the optimization of the energy harvesting ability of wind turbines is developed by using the MFIS fuzzy logic method. Only one parameter (either center or width of MF of fuzzy logic) is optimally updated and optimization of $\mathrm{C}_{\mathrm{p}}$ of a wind turbine is carried out to maximize energy harvesting from the wind. $\mathrm{C}_{\mathrm{p}}$ is enhanced by employing the MFIS. The MFIS optimization technique in combination with the fuzzy logic-based controller of the wind turbine blade pitch drive system achieved $C_{p}$ to improve significantly compared to results of recent researches. Comparing the proposed optimization method result with the factory experimental test result of the SE7715 wind turbine, a $16.74 \%$ improvement in the energy harvesting capacity is attained. These are the novel elements of the proposed scheme. The wind turbine that operates with optimal power conversion coefficient can get increased turbine's speed regulation range, achieves optimal $\mathrm{C}_{\mathrm{p}}$ before it attains rated power, offers improved power curve, and hence increased power generation capacity, and reduces the range of cut-in and rated wind speeds. Practically, a programmable logic-based proportional integral derivative controller is employed in the SE7715 wind turbine. A comparative study between the proposed MFIS optimization method with related recent researches indicates the MFIS optimization improved the energy harvesting capacity of the wind turbine. Practical implementation of MFIS strategy with the developed membership functions tuning optimization method is recommended to enhance the performance of wind turbines.

\section{Conflict of Interest Statement}

The authors declare that they have no competing interests.

\section{References}

[1] David A. Spera, Wind Turbine Technology: Fundamental Concepts of Wind Turbine Engineering. 2nd ed. ASME Press 2009; pp. 295-322. https://doi.org/10.1115/1.802601.

[2] M. Ragheb, Aerodynamics of Rotor Blades, http://magdiragheb.com/NPRE\%20475\%20Wind\%20Power\% 20Systems/Aerodynamics\%20of\%20Rotor\%20Blades.pdf, 2018.

[3] X. Jing, Modeling and control of a doubly-fed induction generator for wind turbine- generator systems. MSc Thesis, Marquette University 2012; pp. 29-30.

[4] M. Sarvi, Sh. Abdi, S. Ahmadi, A New Method for Rapid Maximum Power Point Tracking of PMSG Wind Generator using PSO-Fuzzy Logic. Tech J Engin \& App Sci. 2013; 3 (17): 1984-1995.

[5] Jens Nørkær Sørensen, General Momentum Theory for Horizontal axis wind turbines. Research Topics in Wind Energy 4, 2016; pp. 49-85.

[6] Robert E. Wilson, Peter B. S. Lissaman, Stel N. Walker, Aerodynamic Performance of Wind Turbines: Final Report.
Energy Research and Development Administration, Division of Solar Energy, U.S. 1976; pp. 85.

[7] Y. Sreenivasa Rao, A. Jaya Laxmi, Fuzzy logic based indirect Vector Control of Induction generator in Wind Energy Conversion System. International conference on power, Signal, Control and Computation IEEE 2012. doi: 10.1109/EPSCICON.2012.6175259.

[8] Ranjan Vepa, Dynamic Modeling, Simulation and Control of Energy Generation. Lecture Notes in Energy, Springer-Verlag London 2013; 20: 152-183.

[9] Ayushi Sachan, Akhilesh Kumar Gupta, Paulson Samuel, A Review of MPPT Algorithms Employed in Wind Energy Conversion Systems. Journal of Green Engineering 2016; 6 (4): 385-402. https://doi.org/10.13052/jge1904-4720.643.

[10] Soumia EL HANI, Said GUEDIRA, Noureddine EL ALAMI, Maximum power tracking control wind turbine based on a permanent magnet synchronous generator with a complete converter. International Journal of Smart Grid and Clean Energy 2014; 3 (1): 15-21.

[11] Jogendra Singh Thongam, Mohand Ouhrouche, MPPT Control Methods in Wind Energy Conversion Systems. Fundamental and Advanced Topics in Wind Power 2011; 15: 339- 360. DOI: $10.5772 / 21657$.

[12] Dinh-Chung Phan, Shigeru Yamamoto, Maximum Energy Output of a DFIG Wind Turbine Using an Improved MPPT-Curve Method. Energies 2015; 8: 11718-11736. doi: 10.3390/en81011718.

[13] Zongze Cui, Liwei Song, Shupei Li, Maximum Power Point Tracking Strategy for a New Wind Power System and Its Design Details. IEEE Transactions on Energy Conversion 2017; 32 (3), 1063-1071. doi: 10.1109/tec.2017.2694008.

[14] Godswill Ofualagba, Emmanuel Ubeku, Wind Energy Conversion System- Wind Turbine Modeling. IEEE Power and Energy Society General Meeting 2008; doi: 10.1109/PES.2008.4596699.

[15] V. Kumar, R. R. Joshi, \& R. C. Bansal, Optimal Control Matrix Converter based WECS for Performance Enhancement and Efficiency optimization. IEEE Transaction Energy Conversion 2009; 24 (1): 264-273. doi: 10.1109/TEC.2008.2008921.

[16] D. Petkovic, Ž. Cojbašic, V. Nikolic, Adaptive neuro-fuzzy approach for wind turbine power coefficient estimation. Renewable and Sustainable Energy Reviews 2013; 28 (c): 191-195. doi: 10.1016/j.rser.2013.07.049.

[17] R. Sitharthan, T. Parthasarathy, S. Sheeba Rani, KC. Ramya, An improved radial basis function neural network control strategy-based maximum power point tracking controller for wind power generation system. Transactions of the Institute of Measurement and Control 2019; 41 (11): 1-13. https://doi.org/10.1177/0142331218823858.

[18] L. Saad, H. Hicham, F. Khalid, Optimal Tracking, Modeling, and Control of Aero-generator based on PMSG driven by wind turbine. $5^{\text {th }}$ International Conference on Renewable Energy Research and Applications IEEE 2016; 891-896. doi: 10.1109/ICRERA.2016.7884464.

[19] Y. Soufi, S. Kahla and M. Bechouat, Particle swarm optimization-based sliding mode control of variable speed wind energy conversion system. International Journal of Hydrogen Energy 2016; 41 (45): 20956-20963. 
[20] A. Ghaffari, M. Krstic, Power Optimization and Control in Wind Energy Conversion Systems Using Extremum Seeking. IEEE Transaction on Control Systems Technology 2014; 22 (5): 1684-1695. doi: 10.1109/TCST.2014.2303112.

[21] Tony Hawkins, Maximization of Power Capture in Wind Turbines using Robust Estimation and Lyapunov Extremum Seeking Control. B.S., Kansas State University 2010; 34-62.

[22] Vaughn N, Wind Energy Renewable Energy and the Environment. $2^{\text {nd }}$ ed. CRC Press Taylor \& Francis Group LLC 2014; 115-129.

[23] Abdel-Raheem Youssef, Hossam H. H. Mousa, Essam E. M. Mohamed, Development of Self-Adaptive P\&O MPPT Algorithm for Wind Generation Systems with Concentrated Search Area, Renewable Energy. March 2020. https://doi.org/10.1016/j.renene.2020.03.050.

[24] Wagner Barth Lenz, Angelo Marcelo Tusset, Mauricio Ap. Ribeiro, Jose Manoel Balthazar, Neuro-fuzzy control on horizontal axis wind turbine. Meccanica, January 2020. https://doi.org/10.1007/s11012-019-01118-9.

[25] Abdel-Raheem, Youssef Mahmoud, A. Sayed M. N. Abdel-Wahab, Gaber Shabib Salman, Maximum Power Point Tracking of A Wind Power System Based on Five Phase PMSG using Optimum Torque Control.1 $7^{\text {th }}$ MEPECON, Mansoura University, Egypt, 2015.

[26] Hamed HABIBI, Hamed RAHIMI NOHOOJI, Ian HOWARD, Power maximization of variable-speed variable-pitch wind turbines using passive adaptive neural fault-tolerant control. Frontiers of Mechanical Engineering April 2017. DOI 10.1007/s11465-017-0431-4.

[27] Hamed Habibi, Aghil Yousefi Koma, Ian Howard, Power Improvement of Non-Linear Wind Turbines during Partial Load Operation using Fuzzy Inference Control. CEAI 2017; 19 (2): 31-42.

[28] Ali El Yaakoubi, Adel Asselman, A. Djebi, El Hassan Aroudam, A MPPT Strategy Based on Fuzzy Control for a Wind Energy Conversion System. Procedia Technology 2016; 22: 697-704. doi: $10.1016 /$ j.protcy.2016.01.145.

[29] Sanaz Sabzevari, Ali Karimpour, Mohammad Monfared, and Mohammad Bagher Naghibi Sistani, MPPT control of wind turbines by direct adaptive fuzzy-PI controller and using ANN-PSO wind speed estimator, Journal of Renewable $\begin{array}{llll}\text { Sustainable } & \text { Energy 2017; 9: } 013302 .\end{array}$ https://doi.org/10.1063/1.4973447

[30] A. E. Yaakoubi, L. Amhaimar, K. Attari, M. H. Harrak, M. E. Halaoui, A. Asselman, Non-linear and intelligent maximum power point tracking strategies for small size wind turbines: Performance analysis and comparison. Energy Reports 2019; 5: 545-554. https://doi.org/10.1016/j.egyr.2019.03.001.

[31] Gaber EL-Saady Ahmed, EL-Noby Ahmed Ibrahim, Hazem Hassan Ali, Optimum Power Point Tracking of Variable Speed Wind Turbine DFIG using Genetic Algorithm. IJETT 2016; 37 (7). DOI: 10.14445/22315381/IJETT-V37P264.

[32] Salah Tamalouzt, Kassa Idjdarene, Toufik Rekioua, Rachid Abdessemed, Direct torque control of wind turbine driven doubly fed induction generator. Rev. Roum. Sci. Techn. Électrotechn. et Énerg. 2016; 61 (3): 244-249.

[33] S. M. Muyeen, A. Al-Durra, J. Tamura, Variable speed wind turbine generator system with current-controlled voltage source inverter. Energy Conversion and Management 2011; 52 (7): 2688-2694. doi: 10.1016/j.enconman.2011.02.001.

[34] L. M. Fernández, C. A. García, J. R. Saenz and F. Jurado, Equivalent models of wind farms by using aggregated wind turbines and equivalent winds. Energy Conversion and Management 2009; $50 \quad$ (3): $691-704$. https://doi.org/10.1016/j.enconman.2008.10.005.

[35] Devashish, Amarnath Thakur, Swetapadma Panigrahi, R R Behera, A Review on Wind Energy Conversion System and Enabling Technology. ICEPES. IEEE 2016; 527- 532.

[36] Nazmul Siddique, Intelligent Control-A Hybrid Approach Based on Fuzzy Logic, Neural Networks, and Genetic Algorithms. SCI, Springer International Publishing Switzerland 2014; 517: p. 79.

[37] Ehsan Hosseini, Ghazanfar Shahgholian, Different Types of Pitch Angle Control Strategies Used in Wind Turbine System Applications. JREE 20174; 4 (1): p. 20-35. doi. 10.30501/jree.2017.70103.

[38] Sanjay Krishnankutty Alonso, Membership Functions. eMathTeacher: Mamdani's Fuzzy Inference Method. www.dma.fi.upm.es > fuzzy > fuzzyinf $>$ funpert_en.

[39] Yan Shi, Masaharu Mizumoto, Naoyoshi Yubazaki, Masayuki Otani, A Learning Algorithm for Tuning Fuzzy Rules Based on the Gradient Descent Method, 1996 IEEE, pp. 55-61.

[40] L. X, Wang, J. M. Mendel, Back-propagation fuzzy system as nonlinear dynamic system identifiers, Proceedings of the IEEE International Congress on Fuzzy Systems, San Diego, 1992, 1409-1416.

[41] Jason Brownlee (2020) Machine Learning Mastery: Understand the Impact of Learning Rate on Neural Network Performance. https://machinelearningmastery.com. 